\title{
Sodium and Its Role in Cardiovascular Disease - The Debate Continues
}

\author{
Yee Wen Kong', Sara Baqar1,2, George Jerums ${ }^{1,2}$ and Elif I. Ekinci, ${ }^{1,2,3 *}$ \\ 'Department of Endocrinology, Austin Health, Heidelberg, VIC, Australia, ${ }^{2}$ Department of Medicine, Austin Health, \\ The University of Melbourne, Melbourne, VIC, Australia, ${ }^{3}$ Menzies School of Health Research, Darwin, NT, Australia
}

Guidelines have recommended significant reductions in dietary sodium intake to improve cardiovascular health. However, these dietary sodium intake recommendations have been questioned as emerging evidence has shown that there is a higher risk of cardiovascular disease with a low sodium diet, including in individuals with type 2 diabetes. This may be related to the other pleotropic effects of dietary sodium intake. Therefore, despite recent review of dietary sodium intake guidelines by multiple organizations, including the dietary guidelines for Americans, American Diabetes Association, and American Heart Association, concerns about the impact of the degree of sodium restriction on

OPEN ACCESS

Edited by:

Greg Smith,

University of New South Wales, Australia

Reviewed by: Andrew James Murphy, Baker IDI Heart and Diabetes Institute, Australia Adela Hruby, Tufts University, USA

${ }^{*}$ Correspondence:

Elif I. Ekinci elif.ekinci@unimelb.edu.au

Specialty section: This article was submitted to Obesity, a section of the journal Frontiers in Endocrinology

Received: 22 September 2016 Accepted: 09 December 2016 Published: 23 December 2016

Citation:

Kong YW, Baqar S, Jerums G and Ekinci El (2016) Sodium and Its Role in Cardiovascular Disease - The

Debate Continues.

Front. Endocrinol. 7:164. doi: 10.3389/fendo.2016.00164 cardiovascular health continue to be raised. This literature review examines the effects of dietary sodium intake on factors contributing to cardiovascular health, including left ventricular hypertrophy, heart rate, albuminuria, rennin-angiotensin-aldosterone system activation, serum lipids, insulin sensitivity, sympathetic nervous system activation, endothelial function, and immune function. In the last part of this review, the association between dietary sodium intake and cardiovascular outcomes, especially in individuals with diabetes, is explored. Given the increased risk of cardiovascular disease in individuals with diabetes and the increasing incidence of diabetes worldwide, this review is important in summarizing the recent evidence regarding the effects of dietary sodium intake on cardiovascular health, especially in this population.

Keywords: sodium intake, salt intake, dietary sodium intake, diabetes mellitus, cardiovascular disease, cardiovascular death, morbidity and mortality, chronic kidney disease

\section{INTRODUCTION}

High dietary sodium intake has been related to high blood pressure for more than 4,000 years (1). The concept that fluid volume influenced arterial pressure was then deduced by Stephan Hales in the early 18th century. He provided the scientific rationale that sodium intake might be related to blood pressure since blood volume is largely determined by its sodium and water content (2). Over the next two centuries, other investigators including Ambard and Beaujard, demonstrated that high sodium intake contributes to high blood pressure in both humans and animals (1). The notion of sodium restriction potentially lowering blood pressure was supported by epidemiological observational studies of communities with habitual low sodium intake $(3,4)$. In communities with low sodium intake, blood pressure tended to be lower and did not rise with age. This led to the hypothesis that, at a population level, blood pressure may be correlated with sodium intake $(3,4)$. Since this early 
body of work, there have been many epidemiological and experimental studies confirming the association between high sodium intake and high blood pressure. As elevated blood pressure was associated with increased risk of cardiovascular disease (5), it was hypothesized that high dietary sodium intake may be associated with increased cardiovascular morbidity and mortality $(5,6)$.

Based on this body of evidence, multiple dietary guidelines for sodium intake have been published (Table 1). The 2010 dietary guidelines for Americans recommended sodium intake to be less than $2,300 \mathrm{mg} /$ day $(100 \mathrm{mmol} / 24 \mathrm{~h})$ for the general population and less than $1,500 \mathrm{mg} /$ day $(65 \mathrm{mmol} / 24 \mathrm{~h})$ for higher risk subgroups who are at least 51 years old or African-Americans or have hypertension, diabetes, or chronic kidney disease (7). However, the American Heart Association (AHA) 2010 guidelines contended this and recommended for sodium intake to be less than $1,500 \mathrm{mg} /$ day $(65 \mathrm{mmol} / 24 \mathrm{~h})$ for the entire U.S. population (8). On the other hand, the World Health Organization (WHO) 2012 guidelines recommended a sodium intake of less than $2,000 \mathrm{mg} /$ day $(87 \mathrm{mmol} / 24 \mathrm{~h}$ ) for adults (9). The American Diabetes Association (ADA) also released a statement in 2008 recommending sodium intake to be less than $2,300 \mathrm{mg} /$ day $(100 \mathrm{mmol} / 24 \mathrm{~h})$ in individuals with hypertension or normotension and less than $2,000 \mathrm{mg} /$ day $(87 \mathrm{mmol} / 24 \mathrm{~h})$ for individuals with diabetes and symptomatic heart failure (10). Furthermore, the Kidney Disease: Improving Global Outcomes (KDIGO) 2012 international guidelines suggested a sodium intake of less than $90 \mathrm{mmol} / 24 \mathrm{~h}$ to prevent progression of chronic renal disease in adults (11).

However, low dietary sodium intake has pleotropic effects, which could contribute to cardiovascular health. Therefore,

\begin{tabular}{|c|c|}
\hline Year & Summary of guidelines \\
\hline 2008 & $\begin{array}{l}\text { ADA: } \\
\text { - Normotension, HTN: }<100 \mathrm{mmol} / 24 \mathrm{~h} \\
\text { - DM, symptomatic HF: }<86 \mathrm{mmol} / 24 \mathrm{~h}\end{array}$ \\
\hline \multirow[t]{2}{*}{2010} & $\begin{array}{l}\text { HHS and USDA: } \\
\text { - General population: <100 mmol/24 h } \\
\text { - Age } \geq 51 \text {, African-American HTN, DM, and CKD: } \\
<65 \mathrm{mmol} / 24 \mathrm{~h}\end{array}$ \\
\hline & AHA: $<65$ mmol/24 h for entire U.S. population \\
\hline 2012 & $\begin{array}{l}\text { WHO: }<86 \mathrm{mmol} / 24 \mathrm{~h} \\
\mathrm{KDIGO}:<90 \mathrm{mmol} / 24 \mathrm{~h}\end{array}$ \\
\hline $2013^{a}$ & $\begin{array}{l}\text { ADA: }<100 \mathrm{mmol} / 24 \mathrm{~h} \text {, further reductions on individual basis } \\
\text { AHA: ideally }<65 \mathrm{mmol} / 24 \mathrm{~h} \\
\text { NHMRC: ideally }<70 \mathrm{mmol} / 24 \mathrm{~h}\end{array}$ \\
\hline 2014 & ASH and ISH: reduce sodium intake, but no target level \\
\hline 2015 & HHS and USDA: $<100 \mathrm{mmol} / 24 \mathrm{~h}$ \\
\hline
\end{tabular}

ADA, American Diabetes Association; AHA, American Heart Association; WHO, World Health Organization; KDIGO, Kidney Disease: Improving Global Outcomes; HHS and USDA, U.S. Department of Health and Human Services and U.S. Department of Agriculture; ASH and ISH, American Society of Hypertension and International Society of Hypertension; NHMRC, National Health and Medical Research Council. HTN, hypertension; DM, diabetes mellitus; $H F$, heart failure; $C K D$, chronic kidney disease; $B P$, blood pressure.

aOM: no clear evidence showing that guidelines for sodium intake $<100 \mathrm{mmol} / 24 \mathrm{~h}$ is beneficial or harmful. No evidence that subgroups should have different sodium intake guidelines. rationalizing that low sodium intake reduces adverse cardiovascular outcomes based on its blood pressure lowering effects alone may not be appropriate. In 2013, the Institute of Medicine (IOM) in the U.S. examined the evidence on the effect of dietary sodium intake on health outcomes in the U.S. general population and higher risk subgroups (12). It was concluded that there was a lack of clear scientific evidence showing benefit or harm of reducing sodium intake to recommended levels ( $<100 \mathrm{mmol} / 24 \mathrm{~h})$ (12). There was also limited evidence supporting different dietary sodium guidelines for higher risk subgroups (12). Since then, guidelines for dietary sodium intake have been revised. The 2015-2020 dietary guidelines for Americans now recommend sodium intake to be less than $2,300 \mathrm{mg} /$ day $(100 \mathrm{mmol} / 24 \mathrm{~h})(13)$. The ADA supports this and also comments that further reductions in sodium intake need to be considered on an individual basis for those with diabetes and hypertension (14). In addition, the AHA 2013 guidelines now specify that their current sodium intake recommendations of no more than 2,400 $\mathrm{mg} /$ day $(104 \mathrm{mmol} / 24 \mathrm{~h}$ ) and ideally less than $1,500 \mathrm{mg}$ /day $(65 \mathrm{mmol} / 24 \mathrm{~h})$ are targeted toward reducing blood pressure (15). The American Society of Hypertension (ASH) and International Society of Hypertension (ISH) also suggest reducing sodium intake but do not recommend a target level (16).

In Australia, the National Health and Medical Research Council (NHMRC) recommended sodium intake to be ideally less than $1,600 \mathrm{mg} /$ day $(70 \mathrm{mmol} / 24 \mathrm{~h})$ and at a maximum of $2,300 \mathrm{mg} /$ day $(100 \mathrm{mmol} / 24 \mathrm{~h})$ for adults in 2013 (17). This recommendation was supported by the National Heart Foundation of Australia who also suggested for sodium intake to be less than 2,300 $\mathrm{mg} /$ day $(100 \mathrm{mmol} / 24 \mathrm{~h}$ ) for adults and 1,600 mg/day (70 $\mathrm{mmol} / 24 \mathrm{~h}$ ) for those with hypertension (18).

\section{MATERIALS AND METHODS}

A literature search in MEDLINE (1946-July 2016) was performed using a combination of the following search terms: salt, salt intake, dietary salt intake, dietary sodium intake, dietary sodium, dietary sodium chloride (adverse effects, antagonists, and inhibitors, urine), hypertension, heart rate, immune system, cardiovascular, cardiovascular disease, cardiovascular mortality, mortality, diabetes, type 2 diabetes, and type 1 diabetes. Combinations of limitations including English language, core clinical journals, and journal article were placed on the search terms. References from the relevant papers were also sourced.

\section{DISCUSSION}

\section{Effects of Sodium Intake on Blood Pressure}

Recommendations to reduce sodium intake have been based on the prevailing view that high sodium intake is detrimental to blood pressure, which is a surrogate endpoint for cardiovascular morbidity and mortality (19). There is overwhelming evidence to support that higher sodium intake is associated with elevated blood pressure $(1,3,4,6,20-23)$. This is consistent in both experimental animal models and human studies (6). Conversely, 
sodium restriction is associated with reduced blood pressure $(6,22,23)$. Lower sodium intake, however, may have pleotropic effects (Table 2).

\section{Effects of Sodium on Cardiovascular Health}

Over the recent years, dietary sodium has been shown to have other effects such as impacting on rennin-angiotensinaldosterone system, left ventricular hypertrophy, heart rate, albuminuria (microalbuminuria/proteinuria), insulin sensitivity, lipids, immune function, endothelial dysfunction, and sympathetic nervous system activity.

However, studies demonstrating the effects of dietary sodium on these factors have demonstrated inconsistent results. The discrepancy in results may be attributed to methodological differences among studies. This includes differences in the methods of measurement and ranges of dietary sodium intake, study populations, study outcomes, and failure to explore non-linear associations (24). Many of the methodological controversies pertain to the accuracy in measuring dietary sodium intake (25). Twenty-four hours urine collection is considered the gold standard method for estimating sodium intake because approximately $>90 \%$ of ingested sodium is excreted in the urine in healthy individuals (25). However, we have previously demonstrated that the intraindividual day-to-day variability of a single 24-h urine collection is approximately $20 \%$ (26). As such, averaging multiple 24-h urine collections to minimize random error from day-to-day variability in sodium intake provides the most accurate estimation of an individual's usual sodium intake (25). This is dependent on measures to identify and reduce under-collection or over-collection of these 24-h urine collections (25).

However, many studies estimate dietary sodium intake through dietary surveys or overnight and spot urine collections due to the lower burden on participants (25). Dietary surveys tend to underestimate dietary sodium intake by $30-50 \%$ due to underreporting, difficulty in measuring discretionary sodium use at the table and in cooking, and incomplete food composition databases $(25,26)$. Moreover, food composition databases can vary greatly in their approximations of the nutrient content in foods, depending on the food manufacturers, the methods in measuring nutrient content, natural variations in food composition, and frequency of updates to the food databases (27). This can further compound the inaccuracy in sodium intake estimations in dietary surveys. In addition, the validity of different dietary assessment tools is variable due to their limitations. Twenty-four hours dietary recalls do not reflect long-term dietary patterns and a single 24 -h dietary recall does not account for daily variability

TABLE 2 | Favorable versus unfavorable effects of reduced dietary sodium intake.

\begin{tabular}{ll}
\hline Favorable effects & Unfavorable effects \\
\hline$\downarrow$ Blood pressure & $\uparrow$ Cholesterol \\
$\downarrow$ Left ventricular hypertrophy & $\uparrow$ Catecholamines \\
$\uparrow$ Antiproteinuric effect of drugs for & $\uparrow$ Renin-angiotensin-aldosterone \\
albuminuria & system activation \\
$\downarrow$ Pro-inflammatory state &
\end{tabular}

in dietary intake (25). Conversely, food frequency questionnaires have the potential for recall bias (25). Therefore, the degree of imprecision in estimating dietary sodium intake can also be contributed by the choice of dietary assessment tool.

On the other hand, overnight and spot urine collections are weak surrogates for 24-h urine collections because they have not been sufficiently validated and could underestimate or overestimate 24 -h urinary sodium excretion $(25,28)$. Although several formulae have been proposed to reliably approximate 24-h urinary sodium excretions with overnight and spot urine collections, this has been controversial because overnight and spot urine collections can vary with different genders, ethnic groups, hydration status, and duration and volume of urine collection (28). Moreover, urinary sodium excretion is also affected by diurnal variation (25). Therefore, overnight and spot urine collections are unlikely to be satisfactory substitutes for 24-h urine collections in estimating an individual's sodium intake.

In addition to the method used to estimate dietary sodium intake, the inconsistency in results could also be attributed to limitations of study design. Since many of the studies, which showed the effect of sodium intake on cardiovascular health are observational studies, they are susceptible to confounders and reverse causation. Potential confounders can be reduced in observational studies through restricting or matching participants and performing stratified or multivariate analysis (29). However, this is not applicable to unknown confounding variables, which can distort the association between the exposure and outcome of the study (29). In addition, observational studies are susceptible to reverse causation (29). Reverse causation tends to occur in studies that involve individuals with pre-existing cardiovascular morbidity and cardiovascular risk factors. These individuals may be more likely to restrict their sodium intake because of their comorbidities, which can create an association between lower sodium intake and increased cardiovascular morbidity and mortality. However, the increased cardiovascular morbidity and mortality may not be due to lower sodium intake. Conversely, it may be that lower sodium intake is a result of having pre-existing cardiovascular morbidity and risk factors. Therefore, caution is required in the interpretation of causal associations between exposure and outcome in observational studies.

In addition, there is a lack of consistency in definitions of "low," "moderate," and "high" dietary sodium intake and "severe" and "moderate" sodium restriction. For example, many studies used the term "moderate sodium restriction" when the mean or median reduction in dietary sodium intake is less than $120 \mathrm{mmol} / 24 \mathrm{~h}$. However, Grassi et al. used this term despite having a $140 \mathrm{mmol} / 24 \mathrm{~h}$ reduction in sodium intake (mean sodium reduction 129-136 mmol/24 h) (30). Conversely, Ferrara et al. (31) used the term "severe sodium restriction" when there is only a mean sodium reduction of $63-75 \mathrm{mmol} / 24 \mathrm{~h}$. This highlights the importance of having consistent definitions of these terms to facilitate the interpretation of study results. In this review, these terms will be defined based on majority of the studies. Low, moderate, and high dietary sodium intake is defined as less than $120 \mathrm{mmol} / 24 \mathrm{~h}, 120-150 \mathrm{mmol} / 24 \mathrm{~h}$, and more than $150 \mathrm{mmol} / 24 \mathrm{~h}$, respectively. Severe sodium restriction is defined as having mean or median sodium reduction of at least 
$120 \mathrm{mmol} / 24 \mathrm{~h}$ while moderate sodium restriction is defined as mean or median sodium reduction of less than $120 \mathrm{mmol} / 24 \mathrm{~h}$.

\section{Effects of Sodium Intake on Left Ventricular Hypertrophy}

Higher sodium intake was proposed to be associated with left ventricular hypertrophy (32-35), which is an independent predictor of cardiovascular morbidity and mortality (36). In both individuals with normotension and those with untreated essential hypertension, there was a correlation between higher left ventricular mass and higher urinary sodium excretion reflective of a higher sodium intake (32). This substantiated the findings of another study highlighting that dietary sodium intake was the best predictor of the degree of left ventricular hypertrophy in individuals with essential hypertension (34). In addition, Kupari et al. (33) observed that in a random sample of subjects born in 1954 with both systolic blood pressure and sodium intake above the population median, left ventricular mass was the highest. It was suggested that high sodium intake sensitized the heart to the hypertrophic stimulus of pressure load, which could result in the synergistic interaction of dietary sodium intake with blood pressure on left ventricular mass (33). On the other hand, moderate sodium intake restriction (mean sodium reduction of $63-75 \mathrm{mmol} / 24 \mathrm{~h}$ for 6 weeks) in men with inadequately controlled primary hypertension significantly reduced blood pressure and was associated with reductions in left ventricular mass to the same degree as thiazide diuretic therapy (31).

\section{Effects of Sodium Intake on Heart Rate}

Increased heart rate was demonstrated to be independently associated with increased cardiovascular and all-cause mortality $(37,38)$. This may be attributed to its effect on the diastolic period, which is important for the myocardial perfusion of the left ventricle (39). In addition, the long-term load on both the left ventricle and systemic arteries had been proposed to be related to the product of heart rate and systolic blood pressure (39). Therefore, heart rate may play a more important role in cardiovascular health than anticipated. However, the effects of dietary sodium on heart rate have been frequently overlooked in favor of its effects on blood pressure (39). Studies that demonstrated the effects of dietary sodium on heart rate have shown conflicting results. Graudal et al. (40) observed that sodium restriction (sodium reduction of 42-341 mmol/24 h in studies lasting 4-90 days) was independently associated with increased heart rate in healthy individuals and individuals with hypertension. Higher heart rate associated with lower sodium intake may contribute to higher cardiovascular morbidity and mortality. Although a few randomized controlled trials showed a possible dose-response relationship between reduced dietary sodium and increased heart rate, the data were insufficient for a reliable conclusion (40). In contrast, high sodium intake $(250 \mathrm{mmol} / 24 \mathrm{~h}$ for 7 days) was associated with reduced mean 24 -h heart rate in individuals with mild-tomoderate essential hypertension (41). This was also observed in sodium-resistant individuals with hypertension or normotension (sodium intake of up to $300 \mathrm{mmol} / 24 \mathrm{~h}$ ) (39) and healthy normotensive individuals (sodium intake of $154 \mathrm{mmol} / 24 \mathrm{~h}$ for 7 days)
(42). However, a few studies have demonstrated no significant change in heart rate with high sodium intake $(305 \mathrm{mmol} / 24 \mathrm{~h}$ for 7 days) in normotensive individuals (43) or low sodium intake (sodium intake of $80 \mathrm{mmol} / 24 \mathrm{~h}$ for 8 weeks) in individuals with untreated mild-to-moderate essential hypertension (30). Given the discrepancy in results, more studies in this area are required to investigate the relationship between dietary sodium intake and heart rate.

\section{Effects of Sodium Intake on Albuminuria}

Albuminuria is known to be an established risk factor for cardiovascular disease, especially in individuals with diabetes $(44,45)$. This risk increases across the range of urinary albumin excretion, including within the normal range (44). Epidemiological studies demonstrated that increased sodium intake was independently associated with increased urinary albumin excretion $(46,47)$. In individuals with type 1 diabetes, higher dietary sodium intake may be associated with microalbuminuria, especially in overweight individuals (48). This was supported by a randomized controlled trial showing that individuals with type 2 diabetes and microalbuminuria had a greater increase in blood pressure and increase in albumin excretion ratio during high sodium intake (250 $\mathrm{mmol} / 24 \mathrm{~h}$ for 7 days) (49). This was associated with insulin resistance, indicating that insulin resistance could contribute to increased sodium sensitivity of blood pressure and albuminuria (49). The association between higher sodium intake and increased albuminuria was also demonstrated by another study in 270 individuals with type 2 diabetes (50). However, this study showed a reverse $J$-shaped relationship between sodium intake and albuminuria, where both lower (sodium intake of $<170 \mathrm{mmol} / 24 \mathrm{~h}$ ) and higher (sodium intake of $>203 \mathrm{mmol} / 24 \mathrm{~h}$ ) dietary sodium intake were associated with higher urinary albumin excretion (50). On the contrary, Horikawa et al. (51) reported that there was no significant association between overt nephropathy and sodium intake in Japanese individuals with type 2 diabetes aged 40-70 years old. In contrast, blood pressure and urine protein excretion were reduced during modest sodium restriction (mean sodium reduction of $78 \mathrm{mmol} / 24 \mathrm{~h}$ for 4 weeks) in black individuals with hypertension (52). The discrepancies among results from different studies suggest that further investigations are required to establish the effects of dietary sodium intake on albuminuria.

In addition, sodium restriction was shown to potentiate the antiproteinuric effect of drugs used to treat albuminuria (53). These drugs include angiotensin-converting enzyme inhibitors and angiotensin receptor blockers (54). They reduce albuminuria by blocking rennin-angiotensin-aldosterone system in individuals with type 2 diabetes, thereby reducing cardiovascular risk and nephropathy (45). We have reported that the antiproteinuric and antihypertensive effects of angiotensin receptor blockers (losartan) were increased during low sodium intake (mean sodium intake of $80-85 \mathrm{mmol} / 24 \mathrm{~h}$ ) in individuals with type 2 diabetes, hypertension, and albuminuria (53). We have also demonstrated that increased sodium intake through sodium supplementation $(100 \mathrm{mmol} / 2 \mathrm{~h})$ reduced the antialbuminuric effect of angiotensin receptor blockers (telmisartan) with or without hydrochlorothiazide in individuals with hypertension and type 2 diabetes (55). However, it was observed that this blunting effect 
was only in individuals with habitual low sodium intake (24-h urinary sodium excretion of $<100 \mathrm{mmol} / 24 \mathrm{~h}$ ). In individuals with suppressed rennin-angiotensin-aldosterone system due to habitual high sodium intake (24-h urinary sodium excretion of $>200 \mathrm{mmol} / 24 \mathrm{~h}$ ), increased sodium intake does not alter the response to angiotensin receptor blockers (55). Therefore, this suggested that renal albumin excretion can be modulated by dietary sodium intake when the rennin-angiotensin-aldosterone system is not suppressed by habitual low sodium intake, but is not responsive to further increases in dietary sodium intake when the rennin-angiotensin-aldosterone system is suppressed by habitual high sodium intake $(55,56)$. Additionally, angiotensin receptor blockers reduced the relative risk of renal and cardiovascular events to a greater extent during lower dietary sodium intake in individuals with type 2 diabetes complicated by nephropathy (57). In contrast, higher sodium intake attenuated the renal and cardiovascular protective effects of angiotensin receptor blockers in these individuals (57). This was supported by a study, which showed that the antiproteinuric effect of angiotensin-converting enzyme inhibitors (lisinopril) was abolished with high sodium intake $(200 \mathrm{mmol} / 24 \mathrm{~h})$ and was restored with sodium restriction (sodium intake of $50 \mathrm{mmol} / 24 \mathrm{~h}$ ) in individuals with proteinuria aged $26-56$ years old (58).

\section{Effects of Sodium Intake on Renin-Angiotensin-Aldosterone System}

The rennin-angiotensin-aldosterone system evolved over time to maintain sodium and body volume homeostasis (59). This system is therefore important in maintaining sodium and fluid balance during reduced sodium or reduced fluid intake (60). Physiologic compensatory activation of the rennin-angiotensin-aldosterone system may occur during sodium restriction (61). Activation of the rennin-angiotensin-aldosterone system contributes to increased cardiovascular morbidity and mortality (62). Plasma renin activity has been suggested as a surrogate marker of rennin-angiotensin-aldosterone system activation and high plasma renin activity was demonstrated to be an independent predictor of major vascular events and cardiovascular mortality in a population of high-risk individuals with atherosclerosis and/or diabetes (63). This suggests that blockade of the reninangiotensin-aldosterone system may be beneficial for cardiovascular health. However, studies have shown that the aldosterone escape phenomenon can occur in some individuals during long-term blockade of the renin-angiotensin-aldosterone system (64-66). This phenomenon is characterized by increases in plasma aldosterone levels after the initial reduction or lack of change in aldosterone levels with renin-angiotensin-aldosterone system blockade (64). This may be more pronounced in individuals on a sodium restricted diet (66). Therefore, the renoprotective effect of renin-angiotensin-aldosterone system blockade may be reduced in these individuals with lower sodium intake. Despite recognized benefits of renin-angiotensin-aldosterone system blockade in individuals with diabetes, a greater reduction in dietary sodium intake is associated with an increased risk of developing aldosterone escape (66), which may be associated with increased cardiovascular (67) and renal morbidity (64). In individuals with type 1 diabetes and diabetic nephropathy, the degree of aldosterone escape was observed to be associated with a greater decline in glomerular filtration rate (64). Therefore, individuals with diabetes on sodium restriction may require additional aldosterone blockade to achieve optimal renoprotection $(64,65)$. Hence, dietary sodium restriction may not be appropriate in all individuals.

In individuals with mild-to-moderate hypertension, a high renin-sodium profile before and after antihypertensive treatment was independently associated with a higher subsequent risk of myocardial infarction $(68,69)$. He et al. (70) showed that plasma renin activity and plasma aldosterone increased during acute severe sodium restriction (5 days) in individuals with hypertension (mean sodium reduction of $293 \mathrm{mmol} / 24 \mathrm{~h}$ ) and individuals with normotension (mean sodium reduction of $266 \mathrm{mmol} / 24 \mathrm{~h}$ ). In contrast, He and MacGregor (23) reported that there was only a small increase in plasma renin activity and plasma aldosterone with modest sodium restriction over a longer period ( $\geq 4$ weeks) in individuals with hypertension (median 24-h urinary sodium reduction of $78 \mathrm{mmol} / 24 \mathrm{~h}$ ) and individuals with normotension (median 24-h urinary sodium reduction of $74 \mathrm{mmol} / 24 \mathrm{~h}$ ). However, in a meta-analysis of individuals with hypertension or normotension, sodium restriction was shown to significantly increase plasma renin and aldosterone in proportion to the decrease in sodium intake, even in studies with longer duration ( $\geq 4$ weeks) of moderate sodium restriction (sodium reduction of $<100 \mathrm{mmol} / 24 \mathrm{~h}$ ) (22). This suggested that the acute increase in plasma renin and aldosterone might persist if sodium restriction was maintained (22). This was further supported by a more recent meta-analysis, which demonstrated that low sodium intake $(<120 \mathrm{mmol} / 24 \mathrm{~h}$ ) was associated with significant increases in plasma renin and aldosterone, including in studies with a longer period of sodium restriction ( $\geq 4$ weeks) (71). This discrepancy may be explained by the difference in the degree and period of sodium restriction because maximum stimulation of renin-angiotensin-aldosterone system occurred during prolonged very low sodium intake (61). In a crosssectional study, we have demonstrated that in individuals with type 1 and type 2 diabetes, lower 24-h urinary sodium excretion was associated with higher serum aldosterone (72). This was more prominent in those who were not taking medications that would interfere with the renin-angiotensin-aldosterone system. However, we could not detect such a relationship between plasma renin activity and 24-h urinary sodium excretion, which could be partly attributed to the overall reduced plasma renin activity in individuals with diabetes (72). Conversely, in an interventional study, we reported that in individuals with hypertension and type 2 diabetes, plasma renin activity level was significantly higher with habitual "low" sodium intake (mean 24-h urinary sodium excretion of $126 \mathrm{mmol} / 24 \mathrm{~h}$ ) than with habitual high sodium intake (mean 24-h urinary sodium excretion of $256 \mathrm{mmol} / 24 \mathrm{~h}$ ) (73). We have demonstrated that short-term sodium supplementation $(100 \mathrm{mmol} / 24 \mathrm{~h})$ led to a significant reduction in the angiotensin receptor blockers-induced increase in plasma renin activity and a trend toward blunting of the angiotensin receptor blocker-induced increase in serum aldosterone in individuals with type 2 diabetes (73). 


\section{Effects of Sodium Intake on Lipids}

Moderate to severe sodium restriction has adverse effects on serum lipids $(22,74,75)$. Since the risk of cardiovascular disease increases in proportion to serum lipid levels (76), the adverse effects of sodium restriction on serum lipids could contribute to increased cardiovascular risk. Studies demonstrated that total cholesterol and low density lipoprotein cholesterol increased significantly with short-term low sodium intake $(20 \mathrm{mmol} / 24 \mathrm{~h}$ for 1 week) in non-obese normotensive individuals aged 19-78 years old (74) and in healthy men (75). Graudal et al. (22) observed increased total cholesterol and low density lipoprotein cholesterol levels without changes in high-density lipoprotein cholesterol and triglycerides mainly in studies with short-term large reductions in sodium intake (sodium reduction of $>100 \mathrm{mmol} / 24 \mathrm{~h}$ for $<4$ weeks). However, a few studies with long-term moderate sodium restriction (mean sodium reduction of $75 \mathrm{mmol} / 24 \mathrm{~h}$ for $>4$ weeks) in the meta-analysis reported that the effect of sodium restriction on lipids was not statistically significant (22). This suggested that total cholesterol and low density lipoprotein cholesterol were increased during short-term severe sodium restriction, but there were no significant changes in serum lipid levels during long-term moderate sodium restriction in studies with individuals with hypertension or normotension (22). Moreover, another meta-analysis of studies in individuals with hypertension or normotension also demonstrated that increased cholesterol and triglycerides during moderate sodium restriction (median sodium reduction of $81 \mathrm{mmol} / 24 \mathrm{~h}$ ) were in short-term studies ( $<2$ weeks), with no statistical significance in long-term studies ( $\geq 4$ weeks) (71). This was substantiated by studies showing that moderate sodium intake over a longer period did not affect serum lipid concentrations in non-obese normotensive individuals (sodium reduction of $115 \mathrm{mmol} / 24 \mathrm{~h}$ ) (77) and individuals with mild-to-moderate hypertension (mean 24-h urinary sodium reduction of $52 \mathrm{mmol} / 24 \mathrm{~h}$ ) (78). In addition, a meta-analysis of long-term randomized controlled trials ( $\geq 4$ weeks) reported that sodium restriction had no significant effect on serum lipid levels in adults (79). Therefore, this suggested that the extent and duration of sodium restriction could influence its effect on lipid levels.

\section{Effects of Sodium Intake on Glucose Metabolism}

Dietary sodium restriction has also been suggested to adversely affect glucose metabolism and decrease insulin sensitivity (74, $80)$. In addition, its activation of the renin-angiotensin-aldosterone system (61) and sympathetic nervous system (22, 71, 74) may further reduce insulin sensitivity (81-83). The reninangiotensin-aldosterone system has been shown to predominantly mediate reduced insulin sensitivity through angiotensin II (82). Garg et al. (84) reported that short-term severe salt restriction (24-h urinary sodium excretion of $<20 \mathrm{mmol} / 24 \mathrm{~h}$ for 7 days) was independently associated with increased insulin resistance in healthy individuals. However, although plasma renin activity, angiotensin II levels, 24-h urine aldosterone, and 24-h urine noradrenaline excretion were also increased during low sodium intake, there were no significant correlations with the increase in insulin resistance (84). This may be related to the small sample size in some studies and differences in the methods used to assess renin-angiotensin-aldosterone system and sympathetic nervous system activity. When the insulin-sensitive target tissues, such as skeletal muscle, are less responsive to insulinmediated glucose uptake, more insulin secretion is required (80). Therefore, it was proposed that the reduced insulin sensitivity during sodium restriction could contribute to hyperinsulinism $(74,80)$, which can in turn induce insulin resistance (85) and is associated with cardiovascular disease and type 2 diabetes (78). One study observed that in non-obese normotensive individuals aged 19-78 years old, serum insulin was significantly increased during short-term low sodium intake (20 mmol/24 h for 1 week), indicating impaired glucose metabolism (74). Another study supported this by demonstrating that insulin-mediated glucose disposal during euglycemic clamp conditions was lower with short-term low sodium intake in normotensive individuals. This showed that insulin sensitivity was reduced during short-term low sodium intake (sodium intake of $20 \mathrm{mmol} / 24 \mathrm{~h}$ for 6 days) (80). However, Luther et al. (60) reported that glucose-stimulated insulin secretion was reduced without affecting insulin sensitivity during short-term low sodium intake ( $20 \mathrm{mmol} / 24 \mathrm{~h}$ for 7 days) in normotensive individuals without diabetes. This discrepancy in results could be attributed to methodological differences in measuring outcomes. Therefore, more trials using consistent methods to measure glucose metabolism or insulin sensitivity are required to investigate the effect of low sodium intake on insulin sensitivity. Meland et al. (78) reported that long-term moderate sodium intake (mean 24-h urinary sodium excretion of $125 \mathrm{mmol} / 24 \mathrm{~h}$ for 8 weeks) did not affect insulin sensitivity since fasting insulin, insulin C-peptide, and serum glucose levels were unchanged in individuals with mild-to-moderate hypertension. Therefore, it was suggested that the effect of sodium intake on insulin sensitivity could be related to the degree and period of reduced sodium intake. On the other hand, high sodium intake improved insulin sensitivity (80), especially in individuals with diabetes (86). During high sodium intake $(200 \mathrm{mmol} / 24 \mathrm{~h}$ for 6 days) in healthy lean normotensive individuals, the insulinmediated glucose disposal during euglycemic clamp conditions was increased, indicating increased insulin sensitivity (80). This was substantiated by another study demonstrating that sodium loading with $8 \mathrm{~g}$ of salt a day $(136 \mathrm{mmol} / 24 \mathrm{~h})$ to achieve high sodium intake ( 24 -h urinary sodium of $252 \mathrm{mmol} / 24 \mathrm{~h}$ ) reduced the glycemic and insulinemic response to glucose in individuals with hypertension and type 2 diabetes (86). This showed that glucose tolerance and insulin resistance could be improved with sodium supplementation.

\section{Effects of Sodium Intake on Sympathetic Nervous System Activity}

Sodium restriction also leads to the compensatory stimulation of the sympathetic nervous system $(22,71,74)$, which has multiple adverse effects on the cardiovascular system, including left ventricular hypertrophy progression, vascular remodeling, arterial stiffness, and atherosclerosis (87). This could lead to increased cardiovascular risk. In individuals with hypertension or normotension, low sodium intake $(<120 \mathrm{mmol} / 24 \mathrm{~h})$ was 
associated with increased plasma adrenaline and noradrenaline (71). In addition, Graudal et al. (22) reported that the increase in noradrenaline was observed mainly in short-term studies ( $<4$ weeks). This was supported by a study demonstrating an increase in plasma noradrenaline concentration during shortterm low sodium intake ( $20 \mathrm{mmol} / 24 \mathrm{~h}$ for 1 week) in non-obese normotensive individuals aged 19-78 years old (74). However, Grassi et al. (30) showed that in individuals with untreated essential hypertension, a low sodium intake of $80 \mathrm{mmol} / 24 \mathrm{~h}$ increased sympathetic stimulation and this effect was maintained despite ongoing sodium restriction for 8 weeks. In contrast, a meta-analysis of randomized controlled trials demonstrated that there was no change in catecholamines and sympathetic tone with long-term moderate sodium restriction in individuals with hypertension (median 24-h urinary sodium reduction of $78 \mathrm{mmol} / 24 \mathrm{~h}$ ) and individuals with normotension (median 24-h urinary sodium reduction of $74 \mathrm{mmol} / 24 \mathrm{~h}$ ) (23). This was substantiated by a meta-analysis of long-term randomized controlled trials ( $\geq 4$ weeks) showing that sodium restriction had no effect on urinary and plasma adrenaline and noradrenaline (79). The inconsistency in results was suggested to be related to the extent and duration of sodium restriction. In short-term severe sodium restriction (median of 7 days, mean sodium reduction of $196 \mathrm{mmol} / 24 \mathrm{~h}$ ), there were significant increases in noradrenaline (22). In contrast, there was no such significant change in noradrenaline in long-term moderate sodium restriction (median sodium reduction of $78 \mathrm{mmol}$ for a median of 6 weeks in individuals with hypertension, median sodium reduction of $74 \mathrm{mmol} / 24 \mathrm{~h}$ for a median of 4 weeks in individuals with normotension) (23). Despite the association between the increase in muscle sympathetic nerve activity and concomitant increase in plasma noradrenaline during sodium restriction (30), the discrepancy in results could also be explained by methodological differences. Whereas most studies assessed sympathetic stimulation via plasma and/or urinary catecholamines (79), Grassi et al. (30) measured sympathetic stimulation via muscle sympathetic nerve activity (microneurography), which is considered the gold standard method for assessing sympathetic outflow in humans (88). This highlights that more trials are required to elucidate the association between low dietary sodium intake and sympathetic nervous system activity.

\section{Effects of Sodium Intake on Vascular Endothelial Function}

Vascular endothelial dysfunction has been proposed to contribute to the development of atherosclerosis (89), which is involved in the pathogenesis of cardiovascular disease (90). In recent decades, endothelial dysfunction was demonstrated to be associated with high sodium intake in both animal models and humans (89). Since endothelial dysfunction was shown to be predictive of future cardiovascular events (89), it was proposed that high sodium intake could contribute to increased risk of cardiovascular disease. In normotensive Sprague-Dawley rats on a high sodium diet for 4-5 weeks, arteriolar responsiveness to endothelium-dependent vasodilation induced by acetylcholine was decreased during high sodium intake (91). This was attributed to impaired microvascular endothelial function since responsiveness of vascular smooth muscle to nitric oxide was unaffected by high sodium intake. It was suggested that this was related to the stimulation of increased oxidant levels by high sodium intake through increased generation of reactive oxygen species in the microvascular endothelium (91). A study suggested that the increased generation of reactive oxygen species could be partly due to increased activity of $\mathrm{NAD}(\mathrm{P}) \mathrm{H}$ oxidase and xanthine oxidase, which are oxidant enzymes that produce superoxide anions (92). It was hypothesized that reactive oxygen species could contribute to reduced bioavailability of nitric oxide since the half-life of nitric oxide is reduced when superoxide anions are present (92). Given that nitric oxide plays an important role in vascular function by promoting vasodilation and inhibiting platelet and leukocyte activation (90), reduced nitric oxide bioavailability could contribute to impaired endothelial function in the microvasculature during high sodium intake (91) and may therefore contribute to the pathogenesis of atherosclerosis.

However, other studies demonstrated that low sodium intake was associated with endothelial dysfunction (93-95). Tikellis et al. (94) observed that 6 weeks of low sodium diet was associated with a fourfold increase in plaque accumulation in the aorta, increased vascular inflammation, and renin-angiotensin-aldosterone system activity in atherosclerosis-prone apolipoprotein $\mathrm{E}$ knockout mice. Diabetic apolipoprotein E knockout mice were also reported to have increased plaque accumulation, vascular inflammation, and renin-angiotensin-aldosterone system activity after 6 weeks of a low sodium diet (95). Conversely, a high sodium diet attenuated plaque accumulation and reduced renin-angiotensin-aldosterone system activity in the diabetic apolipoprotein E knockout mice (95). In dogs on a low sodium diet for 2 weeks, a $60 \%$ reduction in flow-induced dilation in coronary arteries was observed (93). Huang et al. (93) proposed that the associated increase in plasma angiotensin II levels during the low sodium diet induced increased activation of protein kinase $\mathrm{C}$, which upregulated vascular $\mathrm{NAD}(\mathrm{P}) \mathrm{H}$ oxidase to produce superoxide and reduce nitric oxide bioavailability. This may explain why the low sodium diet impaired endothelial response to shear stress (93).

The discrepancy in findings in animal studies was also seen in studies in humans $(96,97)$. During sodium loading (200 $\mathrm{mmol} / 24 \mathrm{~h}$ for 5 days) in young healthy normotensive men on a low-salt diet, Tzemos et al. (97) observed that the acetylcholine-induced endothelium-dependent vasodilation was reduced, indicating a reduction in the stimulated release of nitric oxide from the endothelium. In addition, there was reduced endothelium-dependent vasoconstriction induced by NG-monomethyl-L-arginine (L-NMMA), which indicated that the inhibition of basal release of endothelium-derived nitric oxide was reduced (97). This showed that vascular endothelial function was impaired during short-term high salt intake (24-h urinary sodium excretion of $225 \mathrm{mmol} / 24 \mathrm{~h}, 5$ days) (97). However, since systolic blood pressure was increased in this study (97), it would be difficult to distinguish the adverse effect of increased sodium intake on endothelial function from that of increased blood pressure. DuPont et al. (96) separated the effect of high sodium intake from that of increased blood pressure by investigating 
endothelium-dependent dilation in healthy sodium-resistant individuals, who have a change of $5 \mathrm{mmHg}$ or less in 24-h mean arterial pressure between low and high sodium diets. It was observed that high sodium intake (300-350 mmol/24 h) reduced endothelium-dependent dilation (96). Since endotheliumindependent dilation was not affected by high sodium intake, it demonstrated that there was no change in vascular smooth muscle responsiveness. Therefore, the reduced endotheliumdependent dilation during high sodium intake was attributed to impaired endothelial function (96). Conversely, sodium restriction improved endothelial function (98). It was reported that an acute increase in flow-mediated dilation was observed after 2 days of moderate sodium restriction (24-h urinary sodium reduction of $42 \mathrm{mmol} / 24 \mathrm{~h}$ ) in obese and overweight individuals. This was sustained even after prolonged sodium restriction (6 weeks) (98). Moreover, there was an association between a greater increase in flow-mediated dilation and a greater decrease in 24-h urinary sodium to creatinine ratio (98). Therefore, this indicated that longterm moderate sodium restriction improved endothelial function (98). This was supported by another study demonstrating that moderate sodium restriction (sodium reduction of $80 \mathrm{mmol} / 24 \mathrm{~h}$ for 4 weeks) improved both macrovascular (conduit arteries) and microvascular (resistance vessels) endothelial function in middle-aged and older adults with moderately elevated systolic blood pressure (99). It was proposed that this could be related to increased nitric oxide and tetrahydrobiopterin $\left(\mathrm{BH}_{4}\right)$ bioavailability and reduced oxidative stress during sodium restriction (99). However, despite the increased bioavailability of $\mathrm{BH}_{4}$, which is an important cofactor for endothelial nitric oxide synthase activity in the endothelial production of nitric oxide (99), there was no change in the expression and activation of endothelial nitric oxide synthase during sodium restriction (99). In contrast, in cultured bovine endothelial cells, increased bath sodium concentrations were observed to reduce endothelial nitric oxide synthase activity (100). On the other hand, Omland et al. (101) showed that low sodium intake ( $10 \mathrm{mmol} / 24 \mathrm{~h}$ for 5 days) was not associated with any significant change in the endothelium-dependent vasodilation to methacholine in healthy individuals. This may be because individuals in this study had a lower sodium intake $(10 \mathrm{mmol} / 24 \mathrm{~h})$ compared to other sodium restriction studies ( $\geq 20 \mathrm{mmol} / 24 \mathrm{~h}$ ). Conversely, in individuals with or without diabetes, García-Ortiz et al. (102) demonstrated a $J$-shaped relationship between quartiles of sodium intake with arterial stiffness parameters and carotid intima-media thickness, which is a commonly used biomarker for arteriosclerosis and future cardiovascular disease risk (103). The discrepancy in results suggests that more studies are required to investigate the association between dietary sodium intake and vascular endothelial function.

\section{Effects of Sodium Intake on Immune Function}

Sodium intake has been proposed to have effects on both the innate and adaptive immune system (104-109), which may impact on atherosclerosis and cardiovascular morbidity and mortality. Atherosclerosis is a major component in the pathogenesis of cardiovascular disease (90) and consists of chronic low-grade inflammation and atherogenesis (110). Oxidized low density lipoproteins involved in atherogenesis (111) are proposed to be one of the leading antigens involved in mediating $\mathrm{T}$ cell infiltration into atherosclerotic plaques (110). This is predominated by $\mathrm{CD} 4^{+} \mathrm{T}$ helper (Th) cells, which predominantly have a Th1 phenotype $(110,112,113)$. Th1 cells are pro-inflammatory cells which activate pro-inflammatory macrophages and cytolytic $\mathrm{CD}^{+} \mathrm{T}$ cells (110). Moreover, the cytokines produced by Th1 cells, especially IFN $\gamma$, are proposed to promote atherogenesis through the activation of macrophages, endothelial cells, and smooth muscle cells (114). Additionally, IFN $\gamma$ also impairs cholesterol efflux and weakens the fibrous cap to destabilize atherosclerotic plaques (114). On the other hand, the role of Th2 cells in atherosclerosis is less clear $(110,113)$. Despite the suggestion that Th2 cells are antiatherogenic $(110,112,114)$, the IL- 4 cytokine produced by these cells has controversial effects $(110,112)$. Studies have shown that IL-4 could have deleterious or no effect on atherosclerosis $(115,116)$. Therefore, the role of IL-4 in atherosclerosis needs to be elucidated. Th17 cells have been demonstrated to be present in atherosclerotic plaques and may have a pathogenic role in atherosclerosis because they are considered to be highly pro-inflammatory (110). The IL-17A cytokine produced by Th17 cells exerts its pro-inflammatory effects through the recruitment of pathogenic macrophages to the region of inflammation (117) and is also an important mediator of angiotensin II-induced hypertension $(105,118)$. Conversely, regulatory $\mathrm{T}$ (Treg) cells are proposed to be protective in atherosclerosis $(110,119)$ because they produce anti-inflammatory cytokines such as IL-10 and TGF $\beta$ and suppress immune responses through direct and indirect mechanisms $(105,107,110)$.

In addition, the innate immune system has also been proposed to be involved in atherosclerosis. Classical lipopolysaccharide (LPS)-induced M1 macrophages are pro-inflammatory and produce pro-inflammatory cytokines, which promote endothelial dysfunction, destabilization of atherosclerotic plaques in advanced atherosclerosis and thrombus formation in acute coronary syndromes (117), and direct the differentiation and proliferation of Th1 and Th17 cell subpopulations (120). On the other hand, alternatively activated M2 macrophages are non-inflammatory and produce anti-inflammatory cytokines such as IL-10 and TGF $\beta$, which inhibit the recruitment of inflammatory cells and production of pro-inflammatory cytokines (117). However, M2 macrophages may have some pro-atherogenic effects because they can produce IL-4 (117). In addition to the controversy mentioned previously, IL-4 also promotes CD36 expression, which is known to be involved in the uptake of oxidized low density lipoproteins and foam cell formation (114).

High sodium intake might be associated with an imbalance in immune homeostasis, with a predisposition toward a pro-inflammatory state (104-109). During high sodium intake, plasma sodium levels are not increased due to the tight regulation of plasma electrolytes by the kidneys (104). However, sodium can accumulate in the skin and muscles via a renal-independent mechanism, resulting in an approximate $40 \mathrm{mM}(40 \mathrm{mmol} / \mathrm{L})$ increase in interstitial sodium compared to plasma in rodents (104). Given that lymphoid tissues have higher osmolarity, the increase in osmolarity in the interstitial compartments can have 
effects on immune cells in these regions $(104,109,121)$. Increased sodium chloride concentrations in vitro (increased by $40 \mathrm{mmol} / \mathrm{L}$ ) have been demonstrated to promote activation of Th17 cells and M1 (pro-inflammatory) macrophages and blunt activation of M2 (non-inflammatory) macrophages and Treg cells (104, 121). The activation and responses of activated M1 macrophages were increased in the presence of higher sodium chloride concentrations in vitro (increase by $40 \mathrm{mmol} / \mathrm{L})(104,121)$. On the other hand, the activation and ability of M2 macrophages to suppress $\mathrm{CD}^{+}$and $\mathrm{CD}^{+} \mathrm{T}$ cell proliferation were blunted (104). However, this was not associated with increased polarization toward the M1 phenotype in macrophages (104). In addition, a study in 20 healthy non-smoking individuals showed that short-term high sodium intake (sodium intake of $256 \mathrm{mmol} / 24 \mathrm{~h}$ for 7 days) was associated with the induction of pro-inflammatory intermediate $\left(\mathrm{CD} 14^{++} \mathrm{CD} 16^{+}\right)$monocytes and increased production of intracellular reactive oxygen species (122). Moreover, it was also associated with increased monocyte-platelet aggregates (122), which play an important role in thrombotic disorders (123). Conversely, short-term low sodium intake (sodium intake of $85.5 \mathrm{mmol} / 24 \mathrm{~h}$ for 7 days) was associated with a regression of these changes (122). This suggested that high sodium intake may be associated with increased inflammation and thrombosis and low sodium intake may reverse these changes. However, the findings of this study may not be applicable to long-term changes in sodium intake. Yi et al. (106) addressed this by investigating the effects of longterm high and low sodium intakes on immune function in six healthy men. In this study, long-term high dietary sodium intake (203 mmol/24 h for $50 \pm 10$ days) was associated with increased monocyte count (106). Conversely, long-term lower dietary sodium intake (sodium intake of $153 \mathrm{mmol} / 24 \mathrm{~h}$ for $50 \pm 10$ days and $102 \mathrm{mmol} / 24 \mathrm{~h}$ for $50 \pm 10$ days) was associated with reduced production of pro-inflammatory cytokines IL-6 and IL-23 and increased production of anti-inflammatory cytokine IL-10 (106).

Serum-and-glucocorticoid-regulated kinase 1 (SGK1) acts as a mediator of sodium homeostasis by regulating sodium reabsorption through activation of epithelium sodium channels $(\mathrm{ENaC})$ in the kidneys (108). Expression of this enzyme can be induced by exogenous sodium and it is involved in impairing Treg function and enhancing Th17 cell differentiation during increased sodium chloride concentrations in vitro and during increased sodium intake in vivo $(107,108)$. Increases in sodium chloride concentrations promoted SGK1 and IL-23 receptor expression and Th17 cell differentiation in a SGK-1-dependent manner in vitro $(40 \mathrm{mmol} / \mathrm{L}$ sodium chloride) and in vivo (mouse models) (108). This was supported by another study, which demonstrated that increased sodium chloride concentrations (increased by $40 \mathrm{mmol} / \mathrm{L}$ ) in vitro promoted the stable induction of human and murine Th17 cells through the activation of the p38/MAPK pathway involving nuclear factor of activated T cells 5 (NFAT5) and SGK1 (109). Moreover, Th17 cells induced under increased sodium chloride conditions exhibit a pathogenic phenotype associated with increased expression of pro-inflammatory cytokines including IL-17A (109). In addition, Treg cells are also affected by increases in sodium chloride concentrations. Hernandez et al. (107) demonstrated that increased sodium chloride concentrations in vitro (increased by $40 \mathrm{mmol} / \mathrm{L}$ in human and murine Treg cells) and in vivo ( 8 and $1 \%$ sodium chloride in immune-deficient NOD-scid IL2Rg ${ }^{\text {null }}$ mouse models) significantly impaired the suppressive function of Treg cells and promoted a pro-inflammatory Th1-type effector phenotype associated with a SGK1-dependent increase in IFN $\gamma$ secretion in Treg cells. This illustrated that $\mathrm{T}$ cell populations can exhibit plasticity depending on the microenvironment and highlights the importance of environmental influences on T helper cell polarization.

Most of the studies investigated the effect of high sodium intake on immune function $(104,105,107-109)$. There is a paucity of data showing the effect of sodium restriction on immune cells. In addition, the studies were mainly performed in vitro or in experimental models where genetic modification is possible (104, 107-109). The evidence in human studies is insufficient and circumstantial (110). Moreover, the focus of many studies was on autoimmune diseases $(107,109)$. Although atherosclerosis involved chronic low-grade inflammation (110), findings from these studies may not be completely translational to cardiovascular disease. Therefore, more studies are required to investigate the effect of sodium restriction on immune cells and its impact on subsequent development of cardiovascular disease in humans.

There is ample evidence demonstrating that the effects of sodium extend beyond blood pressure and contribute to cardiovascular health. As a result, it may not be suitable to derive an association between sodium intake and cardiovascular outcomes based on blood pressure alone. Therefore, studies that explore the association between sodium intake and cardiovascular morbidity and mortality are important.

\section{Association between Sodium Intake and Mortality}

Despite overwhelming evidence supporting the association between high sodium intake and elevated blood pressure (6), the evidence demonstrating a relationship between dietary sodium intake and cardiovascular outcomes is limited and mostly indirect (124). Some studies proposed that there was no association between dietary sodium intake and cardiovascular morbidity and mortality $(125,126)$. A study of older adults in the general population showed that sodium intake was not associated with 10-year mortality, incident cardiovascular disease, and incident heart failure (125). In addition, there was no strong evidence that sodium restriction reduced all-cause mortality and cardiovascular disease morbidity in individuals with hypertension or normotension (126).

In contrast, observational studies and meta-analyses suggested that high sodium intake increased adverse cardiovascular outcomes (79, 127-135) (Figure 1). Tuomilehto et al. (134) reported that higher sodium intake independently predicted increased mortality and risk of coronary heart disease in Finnish individuals aged 25-64 years old. It was observed that the association was more prominent in men who had high BMI $(\geq 27 \mathrm{~kg} /$ $\mathrm{m}^{2}$ ) (134). This finding was supported by studies conducted in the general population aged 25-74 years old (127) and in individuals with prehypertension aged 45-75 years old (systolic blood pressure of $120-139 \mathrm{mmHg}$ or diastolic blood pressure of 80-89 mmHg) (135). Moreover, higher sodium intake was shown to be associated with increased risk of stroke and stroke mortality in the general population $(131,133)$. In addition, a meta-analysis 


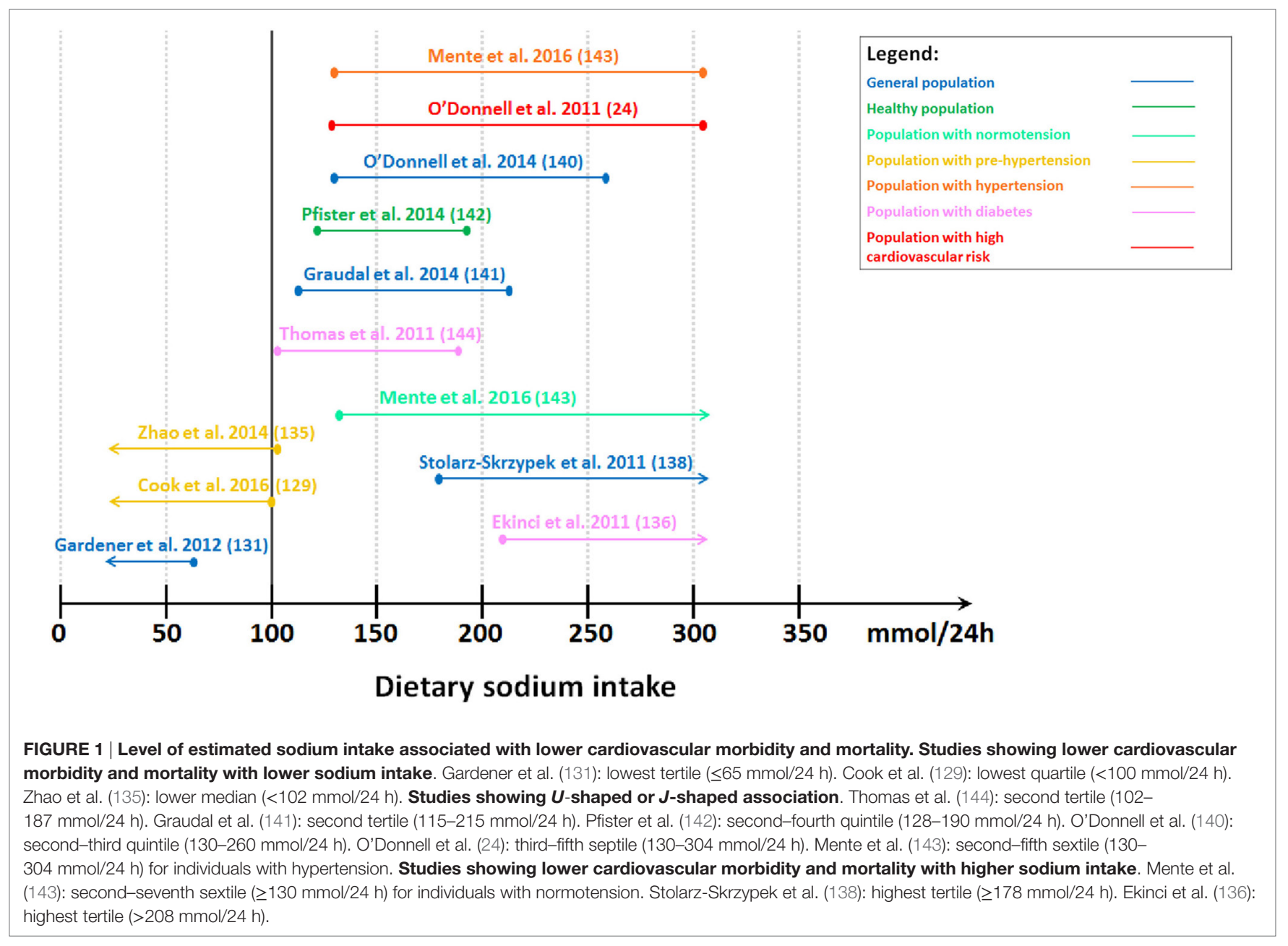

of prospective studies in adults also demonstrated an association between higher sodium intake and increased risk of stroke and total cardiovascular disease (132). On the other hand, a study projected substantial benefits of dietary sodium restriction on reducing cardiovascular outcomes based on the effects of sodium restriction on blood pressure reduction (128). Despite the inappropriate assumption of a linear relationship between sodium intake and blood pressure and between blood pressure and cardiovascular events in this study (128), there are other studies supporting the reduction of cardiovascular morbidity and mortality during sodium restriction $(128,130)$. The observational followup study of Trials of Hypertension Prevention (TOHP) phase I and II showed that lower average sodium intake was associated with reduced mortality in individuals with prehypertension aged 30-54 years old, suggesting that sodium restriction may reduce long-term risk of cardiovascular events in these individuals (129, 130). This relationship was observed even in the lowest range of sodium intake (<100 mmol/24 h) (129). Additionally, Aburto et al. (79) also reported reduced risk of stroke and fatal coronary heart disease with lower sodium intake in adults.

In contrast, we demonstrated that low sodium intake was associated with higher cardiovascular morbidity and mortality in individuals with type 2 diabetes $(136,137)$ (Figure 1). This association was also observed in the general population even after excluding individuals with pre-existing cardiovascular disease $(138,139)$ (Figure 1). Conversely, other studies which followed suggested a $J$-shaped $(24,140)$ or $U$-shaped (141-144) relationship (Figure 1). O'Donnell et al. (140) reported a J-shaped association between cardiovascular events and sodium intake measured by estimated sodium excretion, with a lower risk of death and cardiovascular events when estimated sodium intake was between 3 and $6 \mathrm{~g} /$ day $(130-261 \mathrm{mmol} / 24 \mathrm{~h})$ in the general population aged 35-70 years old in the Prospective Urban Rural Epidemiology (PURE) study. Another study in individuals at high risk of cardiovascular disease supported this by showing that the risk of cardiovascular events was higher with estimated sodium intake less than $3 \mathrm{~g} /$ day $(130 \mathrm{mmol} / 24 \mathrm{~h})$ and greater than $7 \mathrm{~g} /$ day (304 mmol/24 h) (24). In contrast, Pfister et al. (142) showed a $U$-shaped association between sodium intake measured by 24 -h urinary sodium excretion and heart failure in the general population. This $U$-shaped association was also observed between sodium intake and all-cause mortality in individuals with type 1 diabetes without end-stage renal failure (144). A meta-analysis demonstrated that usual sodium intake (115-215 mmol/24 h) had the lowest risk of all-cause mortality and cardiovascular disease events with no difference between the higher and lower 
end of this "normal" range in adults (141). Mente et al. (143) supported this by demonstrating a $U$-shaped association between sodium intake and cardiovascular events and mortality in the general population. However, this relationship was only observed in individuals with hypertension. In individuals with hypertension, a lower sodium intake of less than $3 \mathrm{~g} /$ day $(130 \mathrm{mmol} / 24 \mathrm{~h})$ and higher sodium intake of at least $7 \mathrm{~g} /$ day $(304 \mathrm{mmol} / 24 \mathrm{~h})$ were associated with a higher risk of cardiovascular events and death than a sodium intake of 4-5 g/day (174-217 mmol/24 h). Conversely, in normotensive individuals, only lower sodium intake was associated with increased risk of cardiovascular events and death (143). This suggests that the current recommendations to reduce sodium intake may need to be revaluated.

\section{Differences in Effects of Dietary Sodium Intake on Health in the Diabetes Population Compared to the General Population}

Cardiovascular disease accounts for up to $80 \%$ of deaths in individuals with diabetes (145). Since diabetes is associated with multiple cardiovascular disease risk factors, including hypertension, dyslipidemia, microalbuminuria, and left ventricular hypertrophy (145), which in turn are associated with dietary sodium intake, the impact of sodium intake on cardiovascular morbidity and mortality in diabetes may differ from the general population (Figure 2). Hypertension is present in approximately $70 \%$ of individuals with type 2 diabetes (146) and this further increases cardiovascular disease risk in these individuals (147). Individuals with diabetes were shown to have significantly increased total exchangeable sodium compared to normal individuals (148). This excess body sodium may play an important pathogenetic role in maintaining diabetesassociated hypertension (148). In addition, a high prevalence of sodium sensitivity has been reported in individuals with type 1 diabetes (149) and in individuals with hypertension and type 2 diabetes (150). However, in contrast to individuals without diabetes, low sodium diets did not reduce the reactivity of blood vessels to angiotensin II, indicating that sodium restriction may be less effective for blood pressure control in individuals with hypertension and type 2 diabetes compared to individuals without diabetes (150).

In addition, central sympathetic hyperactivity was reported in individuals with type 2 diabetes, with the greatest sympathetic hyperactivity seen in those with concurrent essential hypertension $(83,151)$. Type 2 diabetes is associated with hyperinsulinemia (78), which is secondary to insulin resistance (145). Hyperinsulinemia has been known to increase sympathetic output through the sympathoexcitatory effects of increased insulin (152). Moreover, Huggett et al. (83) have demonstrated an association between increased sympathetic nervous system activity and increased insulin levels. Therefore, the excessive sympathetic nervous system activation observed in type 2 diabetes may be attributed to increased insulin levels (151). This sustained over-activation of the sympathetic nervous system may contribute to the increased

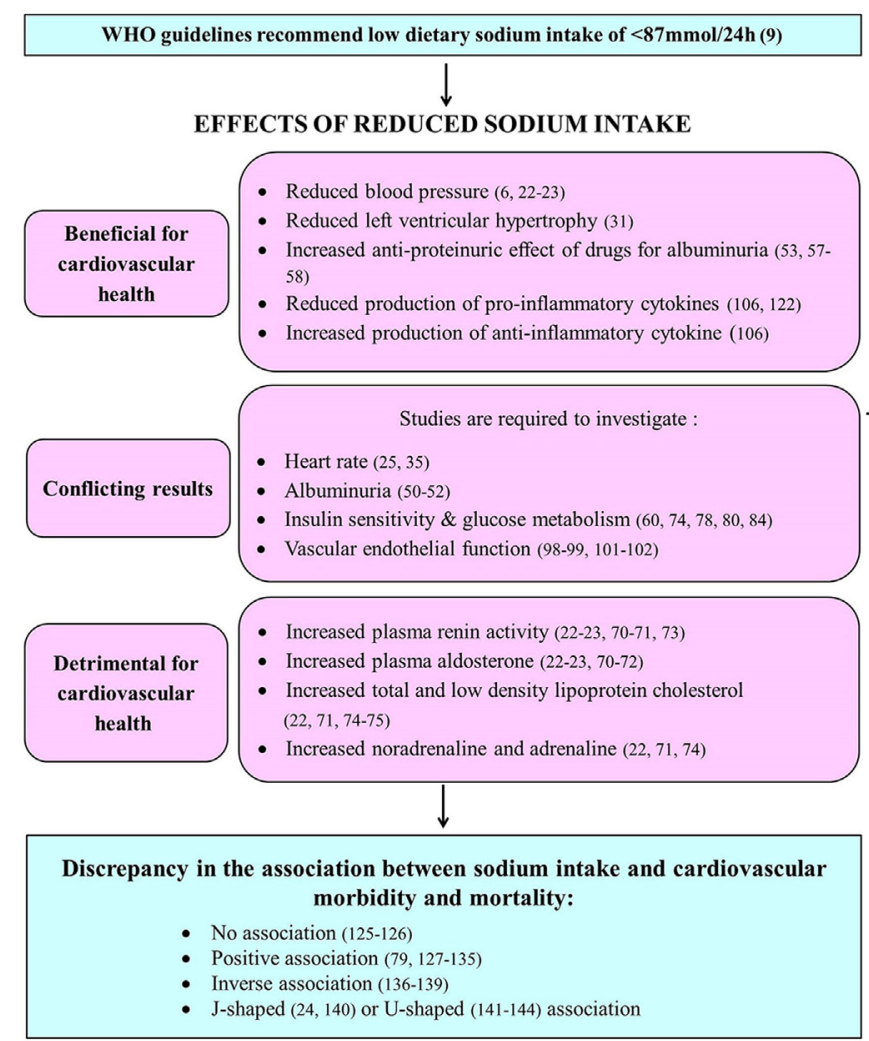

\section{INDIVIDUALS WITH DIABETES ARE DIFFERENT FROM THE} GENERAL POPULATION

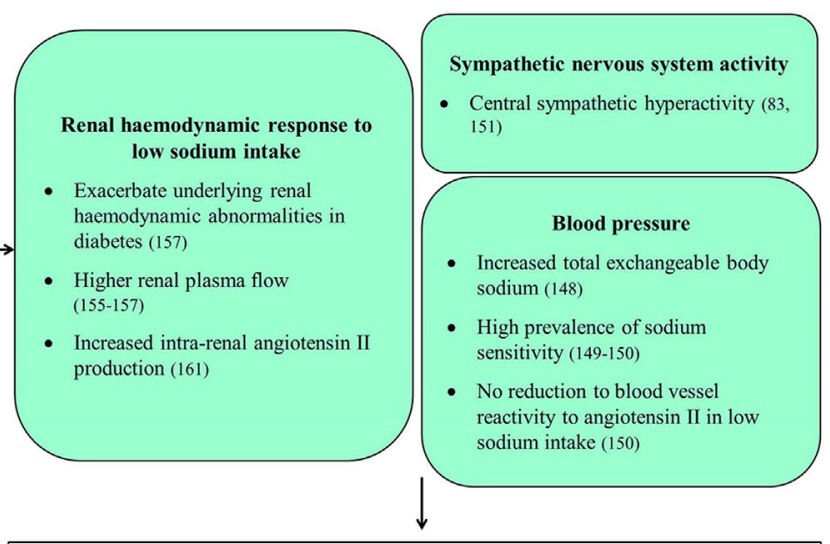

In both Type 1 and 2 diabetes mellitus, low sodium intake was associated with higher cardiovascular morbidity and all-cause mortality (136-137, 144, 164)

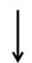

Dietary sodium recommendations for general population may not be suitable for high risk subgroups such as diabetes

FIGURE 2 | Summary of effects of dietary sodium intake on systems contributing to cardiovascular health in those with and without diabetes. 
cardiovascular morbidity and mortality associated with type 2 diabetes (83). As such, the effects of dietary sodium intake on sympathetic nervous system activity may play a more important role in the cardiovascular health of individuals with diabetes.

Diabetic nephropathy is the leading cause of end-stage renal disease worldwide $(153,154)$. Despite the lack of understanding of the pathogenesis of diabetic nephropathy, it was observed that the occurrence of glomerular hyperfiltration in early diabetes contributes to it $(154,155)$. Studies have shown increased glomerular filtration rate and renal plasma flow in individuals with type 1 diabetes and higher effective renal plasma flow in individuals with type 2 diabetes compared to individuals without diabetes (155157). In addition, the renal hemodynamic response to variations in dietary sodium intake may be different in diabetes compared to the general population (154). This is due to primary tubular hyperresorption in early diabetes and the corresponding normal physiologic action of the tubuloglomerular feedback system (154, 158). Glucose and sodium in the renal proximal tubule lumen are reabsorbed via sodium-glucose cotransporters (SGLT) in the luminal side of proximal tubule epithelial cells (159). This is driven by the sodium gradient within these cells, which is generated by the sodium-potassium ATPase pump in the basolateral membrane, thereby facilitating the transport of glucose against a concentration gradient (159). The tubuloglomerular feedback system theory stipulates that increased glucose and sodium reabsorption in the proximal tubules of the kidney during primary tubular hyperresorption in early diabetes leads to reduced sodium concentration at the macula densa, which in turn leads to afferent arteriolar vasodilation to increase glomerular filtration rate, resulting in glomerular hyperfiltration (154). In individuals with type 1 diabetes, sodium restriction was demonstrated to exacerbate the underlying renal hemodynamic abnormalities seen in early disease, including increased glomerular filtration rate and decreased renal vascular resistance (157). In contrast to the increase in effective renal plasma flow associated with higher sodium intake in individuals without diabetes (160), individuals with type 1 diabetes were observed to have significantly higher renal plasma flow during extreme sodium restriction (157). In addition, individuals with type 2 diabetes were reported to have low baseline plasma renin activity (161), which may be associated with an increased risk of developing aldosterone escape (64). They had a heightened renal vasodilator response to angiotensin receptor blockers (irbesartan) despite a limited increase in plasma renin activity during extreme sodium restriction (161). Therefore, it was proposed that plasma renin might not reflect intrarenal renin levels in type 2 diabetes (161). Moreover, the increase in plasma renin activity induced by the angiotensin receptor blocker suggested that there might be increased intrarenal angiotensin II production suppressing plasma renin activity in type 2 diabetes (161).

Given these differences between people with diabetes and the general population (Figure 2), cardiovascular outcomes associated with variations in dietary sodium intake in diabetes may not be the same as that expected of the general population. Therefore, the paradoxical relationship between low sodium intake and higher cardiovascular morbidity and mortality should not be disregarded, especially in patient populations with specific clinical conditions (162).
In individuals with type 1 diabetes, both high and low dietary sodium intakes were shown to be associated with increased all-cause mortality (144). Moreover, in these individuals, there was also an inverse association between sodium intake and the development of end-stage renal disease (144), which is associated with a significantly increased mortality risk (163). As a result, this could contribute to increased mortality risk during low sodium intake in individuals with type 1 diabetes. Lower dietary sodium intake was observed to be associated with higher all-cause and cardiovascular mortality in individuals with type 2 diabetes (136, 164). This was supported by the finding that lower 24 -h urinary sodium excretion over time was also associated with increased all-cause mortality in these individuals (137). Therefore, this suggests that the low dietary sodium intake recommendations for the general population may not be suitable for high-risk subgroups, such as individuals with type 1 diabetes or type 2 diabetes.

\section{CONCLUSION}

Dietary sodium intake recommendations support sodium restriction based on previous evidence suggesting a reduction in blood pressure. It was proposed that this would be associated with a subsequent reduction in cardiovascular morbidity and mortality. However, increasingly, it is now being understood that sodium intake has other pleiotropic effects that affect cardiovascular health, highlighting that the association between sodium intake and cardiovascular outcomes cannot be based on blood pressure alone. Therefore, current dietary sodium intake guidelines have been revised since the IOM reported that there was no clear benefit or harm of sodium restriction to less than $100 \mathrm{mmol} / 24 \mathrm{~h}$ in 2013. However, recently, the current dietary sodium guidelines have been challenged because there is emerging evidence to suggest an associated increase in morbidity and mortality with lower dietary sodium intake in high-risk groups, including those with diabetes. These studies suggest that the current dietary guidelines may be too strict; therefore, they may not be suitable and may need further revision. However, there is a lack of data from randomized controlled trials to determine the optimal level of dietary sodium intake for specific populations. In addition, there is a paucity of data with a lack of randomized controlled trial data in humans to explain the possible mechanisms contributing to the adverse outcomes associated with lower dietary sodium intake in high-risk populations.

\section{AUTHOR CONTRIBUTIONS}

YK undertook the literature review and wrote the first draft of the manuscript. EE, SB, and GJ planned the study, reviewed, and edited the manuscript.

\section{FUNDING}

SB was supported by a National Heart Foundation of Australia Professional Scholarship (\#100287). EE was supported by an NHMRC Early Career Research Fellowship (\#1054312), Viertel Clinical Investigatorship, Sir Edward Weary Dunlop Medical Research Foundation grant and RACP fellowship. 


\section{REFERENCES}

1. Stamler J. The INTERSALT study: background, methods, findings, and implications. Am J Clin Nutr (1997) 65(2):626S-42S.

2. Alderman $\mathrm{MH}$, Cohen HW. Impact of dietary sodium on cardiovascular disease morbidity and mortality. Curr Hypertens Rep (2002) 4(6):453-7. doi:10.1007/s11906-002-0025-2

3. Gleibermann L. Blood pressure and dietary salt in human populations. Ecol Food Nutr (1973) 2(2):143. doi:10.1080/03670244.1973.9990329

4. Freis ED. Salt, volume and the prevention of hypertension. Circulation (1976) 53(4):589-95. doi:10.1161/01.CIR.53.4.589

5. Lewington S, Clarke R, Qizilbash N, Peto R, Collins R, Prospective Studies C. Age-specific relevance of usual blood pressure to vascular mortality: a meta-analysis of individual data for one million adults in 61 prospective studies. Lancet (2002) 360(9349):1903-13. doi:10.1016/S0140-6736(02) 11911-8

6. He FJ, MacGregor GA. Reducing population salt intake worldwide: from evidence to implementation. Prog Cardiovasc Dis (2010) 52(5):363-82. doi:10.1016/j.pcad.2009.12.006

7. U.S. Department of Agriculture and U.S. Department of Health and Human Services. Dietary Guidelines for Americans, 2010. 7th ed. Washington, DC: U.S. Government Printing Office (2010).

8. Lloyd-Jones DM, Hong Y, Labarthe D, Mozaffarian D, Appel LJ, Van Horn L, et al. Defining and setting national goals for cardiovascular health promotion and disease reduction. The american heart association's strategic impact goal through 2020 and beyond. Circulation (2010) 121(4):586-613. doi:10.1161/ CIRCULATIONAHA.109.192703

9. WHO. Guideline: Sodium Intake for Adults and Children. Geneva: World Health Organization (WHO) (2012).

10. Bantle JP, Wylie-Rosett J, Albright AL, Apovian CM, Clark NG, Franz MJ, et al. Nutrition recommendations and interventions for diabetes: a position statement of the American diabetes association. Diabetes Care (2008) 31(Suppl 1):S61-78. doi:10.2337/dc08-S061

11. Kidney Disease: Improving Global Outcomes (KDIGO) CKD Work Group. KDIGO 2012 clinical practice guideline for the evaluation and management of chronic kidney disease. Kidney Int Suppl (2013) 3:1-150.

12. IOM. Sodium Intake in Populations: Assessment of Evidence. Washington, DC: Institute of Medicine (IOM) (2013).

13. U.S. Department of Health and Human Services and U.S. Department of Agriculture. 2015 - 2020 Dietary Guidelines for Americans. 8th ed. Washington, DC: U.S. Government Printing Office (2015).

14. Evert AB, Boucher JL, Cypress M, Dunbar SA, Franz MJ, Mayer-Davis EJ, et al. Nutrition therapy recommendations for the management of adults with diabetes. Diabetes Care (2014) 37(Suppl 1):S120-43. doi:10.2337/ dc14-S120

15. Eckel RH, Jakicic JM, Ard JD, de Jesus JM, Houston Miller N, Hubbard VS, et al. AHA/ACC guideline on lifestyle management to reduce cardiovascular risk: a report of the American College of Cardiology/American Heart Association Task Force on Practice Guidelines. J Am Coll Cardiol (2014) 63(25 Pt B):2960-84. doi:10.1016/j.jacc.2013.11.003

16. Weber MA, Schiffrin EL, White WB, Mann S, Lindholm LH, Kenerson JG, et al. Clinical practice guidelines for the management of hypertension in the community: a statement by the american society of hypertension and the international society of hypertension. J Clin Hyperten0073 (2014) 32(1):3-15. doi:10.1097/HJH.0000000000000065

17. National Health and Medical Research Council. Australian Dietary Guidelines. Canberra: National Health and Medical Research Council (2013).

18. Australia Heart Foundation. Salt. Available from: https://heartfoundation. org.au/healthy-eating/food-and-nutrition/salt

19. Messerli FH, Schmieder RE, Weir MR. Salt. A perpetrator of hypertensive target organ disease? Arch Intern Med (1997) 157(21):2449-52. doi:10.1001/ archinte.1997.00440420077006

20. Cutler JA, Follmann D, Allender PS. Randomized trials of sodium reduction: an overview. Am J Clin Nutr (1997) 65(2):643S-51S.

21. Elliott P, Stamler J, Nichols R, Dyer AR, Stamler R, Kesteloot H, et al. Intersalt revisited: further analyses of 24 hour sodium excretion and blood pressure within and across populations. Intersalt cooperative research group. BMJ (1996) 312(7041):1249-53. doi:10.1136/bmj.312.7041.1249
22. Graudal NA, Galløe AM, Garred P. Effects of sodium restriction on blood pressure, renin, aldosterone, catecholamines, cholesterols, and triglyceride: a meta-analysis. JAMA (1998) 279(17):1383-91. doi:10.1001/ jama.279.17.1383

23. He FJ, MacGregor GA. Effect of modest salt reduction on blood pressure: a meta-analysis of randomized trials. Implications for public health. J Hum Hypertens (2002) 16(11):761. doi:10.1038/sj.jhh.1001459

24. O’Donnell MJ, Yusuf S, Mente A, Gao P, Mann JF, Teo K, et al. Urinary sodium and potassium excretion and risk of cardiovascular events. JAMA (2011) 306(20):2229-38. doi:10.1001/jama.2011.1729

25. Cobb LK, Anderson CA, Elliott P, Hu FB, Liu K, Neaton JD, et al. Methodological issues in cohort studies that relate sodium intake to cardiovascular disease outcomes: a science advisory from the American heart association. Circulation (2014) 129(10):1173-86. doi:10.1161/CIR. 0000000000000015

26. Ekinci EI, Cheong KY, Dobson M, Premaratne E, Finch S, MacIsaac RJ, et al. High sodium and low potassium intake in patients with type 2 diabetes. Diabet Med (2010) 27(12):1401-8. doi:10.1111/j.1464-5491.2010.03111.x

27. Pennington JAT. Applications of food composition data: data sources and considerations for use. J Food Compos Anal (2008) 21(Suppl):S3-12. doi:10.1016/j.jfca.2007.02.005

28. Ji C, Miller MA, Venezia A, Strazzullo P, Cappuccio FP. Comparisons of spot vs 24-h urine samples for estimating population salt intake: validation study in two independent samples of adults in Britain and Italy. Nutr Metab Cardiovasc Dis (2014) 24(2):140-7. doi:10.1016/j.numecd. 2013.06.011

29. Jepsen P, Johnsen SP, Gillman MW, Sørensen HT. Interpretation of observational studies. Heart (2004) 90(8):956-60. doi:10.1136/hrt.2003.017269

30. Grassi G, Dell'Oro R, Seravalle G, Foglia G, Trevano FQ, Mancia G. Short- and long-term neuroadrenergic effects of moderate dietary sodium restriction in essential hypertension. Circulation (2002) 106(15):1957-61. doi:10.1161/ 01.CIR.0000033519.45615.C7

31. Ferrara LA, de Simone G, Pasanisi F, Mancini M, Mancini M. Left ventricular mass reduction during salt depletion in arterial hypertension. Hypertension (1984) 6(5):755-9. doi:10.1161/01.HYP.6.5.755

32. Du Cailar G, Ribstein J, Daures JP, Mimran A. Sodium and left ventricular mass in untreated hypertensive and normotensive subjects. Am J Physiol (1992) 263(1):H177.

33. Kupari M, Koskinen P, Virolainen J. Correlates of left ventricular mass in a population sample aged 36 to 37 years. Focus on lifestyle and salt intake. Circulation (1994) 89(3):1041-50. doi:10.1161/01.CIR.89.3.1041

34. Schmieder RE, Messerli FH, Garavaglia GE, Nunez BD. Dietary salt intake. A determinant of cardiac involvement in essential hypertension. Circulation (1988) 78(4):951-6. doi:10.1161/01.CIR.78.4.951

35. Schmieder RE, Langenfeld MR, Friedrich A, Schobel HP, Gatzka CD, Weihprecht H. Angiotensin II related to sodium excretion modulates left ventricular structure in human essential hypertension. Circulation (1996) 94(6):1304-9. doi:10.1161/01.CIR.94.6.1304

36. Levy D, Garrison RJ, Savage DD, Kannel WB, Castelli WP. Prognostic implications of echocardiographically determined left ventricular mass in the Framingham Heart Study. N Engl J Med (1990) 322(22):1561-6. doi:10.1056/ NEJM199005313222203

37. Ho JE, Larson MG, Ghorbani A, Cheng S, Coglianese EE, Vasan RS, et al. Long-term cardiovascular risks associated with an elevated heart rate: the Framingham Heart Study. JAm Heart Assoc (2014) 3(3):e000668. doi:10.1161/JAHA.113.000668

38. Jensen MT, Marott JL, Allin KH, Nordestgaard BG, Jensen GB. Resting heart rate is associated with cardiovascular and all-cause mortality after adjusting for inflammatory markers: the Copenhagen City Heart Study. Eur J Prev Cardiol (2012) 19(1):102-8. doi:10.1177/1741826710394274

39. Folkow B, Ely D. Importance of the blood pressure-heart rate relationship. Blood Press (1998) 7(3):133-8. doi:10.1080/080370598437321

40. Graudal NA, Hubeck-Graudal T, Jürgens G. Reduced dietary sodium intake increases heart rate. A meta-analysis of 63 randomized controlled trials including 72 study populations. Front Physiol (2016) 7:111. doi:10.3389/ fphys.2016.00111

41. Kawano Y, Abe H, Kojima S, Yoshimi H, Sanai T, Kimura G, et al. Different effects of alcohol and salt on 24-hour blood pressure and heart rate in 
hypertensive patients. Hypertens Res (1996) 19(4):255-61. doi:10.1291/ hypres. 19.255

42. McNeely JD, Windham BG, Anderson DE. Dietary sodium effects on heart rate variability in salt sensitivity of blood pressure. Psychophysiology (2008) 45(3):405-11. doi:10.1111/j.1469-8986.2007.00629.x

43. He M, Mu J, Liu F, Ren K, Wang Y, Guo T, et al. Effects of a high salt intake and potassium supplementation on QT interval dispersion in normotensive healthy subjects. Intern Med (2015) 54(3):295-301. doi:10.2169/ internalmedicine.54.2297

44. Arnlov J, Evans JC, Meigs JB, Wang TJ, Fox CS, Levy D, et al. Low-grade albuminuria and incidence of cardiovascular disease events in nonhypertensive and nondiabetic individuals: the Framingham Heart Study. Circulation (2005) 112(7):969-75. doi:10.1161/CIRCULATIONAHA.105.538132

45. Molitch ME, DeFronzo RA, Franz MJ, Keane WF, Mogensen CE, Parving HH, et al. Nephropathy in diabetes. Diabetes Care (2004) 27(Suppl 1):S79-83. doi:10.2337/diacare.27.2007.S79

46. Verhave JC, Hillege HL, Burgerhof JG, Janssen WM, Gansevoort RT, Navis CJ, et al. Sodium intake affects urinary albumin excretion especially in overweight subjects. J Intern Med (2004) 256(4):324-30. doi:10.1111/j.1365-2796.2004.01390.x

47. du Cailar G, Ribstein J, Mimran A. Dietary sodium and target organ damage in essential hypertension. Am J Hypertens (2002) 15(3):222-9. doi:10.1016/ S0895-7061(01)02287-7

48. Engelen L, Soedamah-Muthu SS, Geleijnse JM, Toeller M, Chaturvedi N, Fuller JH, et al. Higher dietary salt intake is associated with microalbuminuria, but not with retinopathy in individuals with type 1 diabetes: the EURODIAB prospective complications study. Diabetologia (2014) 57(11):2315-23. doi:10.1007/s00125-014-3367-9

49. Vedovato M, Lepore G, Coracina A, Dodesini AR, Jori E, Tiengo A, et al. Effect of sodium intake on blood pressure and albuminuria in Type 2 diabetic patients: the role of insulin resistance. Diabetologia (2004) 47(2):300-3. doi:10.1007/s00125-003-1303-5

50. Sakabe K, Fukui M, Ushigome E, Hamaguchi M, Senmaru T, Yamazaki M, et al. Low daily salt intake is correlated with albuminuria in patients with type 2 diabetes. Hypertens Res (2012) 35(12):1176-9. doi:10.1038/hr.2012.116

51. Horikawa C, Yoshimura Y, Kamada C, Tanaka S, Tanaka S, Hanyu O, et al. Dietary sodium intake and incidence of diabetes complications in Japanese patients with type 2 diabetes: analysis of the Japan Diabetes Complications Study (JDCS). J Clin Endocrinol Metab (2014) 99(10):3635-43. doi:10.1210/ jc.2013-4315

52. Swift PA, Markandu ND, Sagnella GA, He FJ, MacGregor GA. Modest salt reduction reduces blood pressure and urine protein excretion in black hypertensives: a randomized control trial. Hypertension (2005) 46(2):308-12. doi:10.1161/01.HYP.0000172662.12480.7f

53. Houlihan CA, Allen TJ, Baxter AL, Panangiotopoulos S, Casley DJ, Cooper ME, et al. A low-sodium diet potentiates the effects of losartan in type 2 diabetes. Diabetes Care (2002) 25(4):663-71. doi:10.2337/diacare.25.4.663

54. Naidoo DP. The link between microalbuminuria, endothelial dysfunction and cardiovascular disease in diabetes. Cardiovasc J S Afr (2002) 13(4):194-9.

55. Ekinci EI, Thomas G, Thomas D, Johnson C, Macisaac RJ, Houlihan CA, et al. Effects of salt supplementation on the albuminuric response to telmisartan with or without hydrochlorothiazide therapy in hypertensive patients with type 2 diabetes are modulated by habitual dietary salt intake. Diabetes Care (2009) 32(8):1398-403. doi:10.2337/dc08-2297

56. Ekinci EI, Thomas G, MacIsaac RJ, Johnson C, Houlihan C, Panagiotopoulos $S$, et al. Salt supplementation blunts the blood pressure response to telmisartan with or without hydrochlorothiazide in hypertensive patients with type 2 diabetes. Diabetologia (2010) 53(7):1295-303. doi:10.1007/s00125-010-1711-2

57. Lambers Heerspink HJ, Holtkamp FA, Parving HH, Navis GJ, Lewis JB, Ritz E, et al. Moderation of dietary sodium potentiates the renal and cardiovascular protective effects of angiotensin receptor blockers. Kidney Int (2012) 82(3):330-7. doi:10.1038/ki.2012.74

58. Heeg JE, de Jong PE, van der Hem GK, de Zeeuw D. Efficacy and variability of the antiproteinuric effect of ACE inhibition by lisinopril. Kidney Int (1989) 36(2):272-9. doi:10.1038/ki.1989.190

59. Fournier D, Luft FC, Bader M, Ganten D, Andrade-Navarro MA. Emergence and evolution of the renin-angiotensin-aldosterone system. J Mol Med (Berl) (2012) 90(5):495-508. doi:10.1007/s00109-012-0894-z
60. Luther JM, Byrne LM, Yu C, Wang TJ, Brown NJ. Dietary sodium restriction decreases insulin secretion without affecting insulin sensitivity in humans. J Clin Endocrinol Metab (2014) 99(10):E1895-902. doi:10.1210/jc.2014-2122

61. Karppanen H, Mervaala E. Sodium intake and hypertension. Prog Cardiovasc Dis (2006) 49(2):59-75. doi:10.1016/j.pcad.2006.07.001

62. Tomaschitz A, Pilz S, Ritz E, Grammer T, Drechsler C, Boehm BO, et al. Association of plasma aldosterone with cardiovascular mortality in patients with low estimated GFR: the Ludwigshafen Risk and Cardiovascular Health (LURIC) study. Am J Kidney Dis (2011) 57(3):403-14. doi:10.1053/ j.ajkd.2010.10.047

63. Verma S, Gupta M, Holmes DT, Xu L, Teoh H, Gupta S, et al. Plasma renin activity predicts cardiovascular mortality in the Heart Outcomes Prevention Evaluation (HOPE) study. Eur Heart J (2011) 32(17):2135-42. doi:10.1093/ eurheartj/ehr066

64. Schjoedt KJ, Andersen S, Rossing P, Tarnow L, Parving HH. Aldosterone escape during blockade of the renin-angiotensin-aldosterone system in diabetic nephropathy is associated with enhanced decline in glomerular filtration rate. Diabetologia (2004) 47(11):1936-9. doi:10.1007/ s00125-004-1542-0

65. Rump LC. Secondary rise of albuminuria under AT1-receptor blockade what is the potential role of aldosterone escape? Nephrol Dial Transplant (2007) 22(1):5-8. doi:10.1093/ndt/gfl549

66. Moranne O, Bakris G, Fafin C, Favre G, Pradier C, Esnault VL. Determinants and changes associated with aldosterone breakthrough after angiotensin II receptor blockade in patients with type 2 diabetes with overt nephropathy. Clin J Am Soc Nephrol (2013) 8(10):1694-701. doi:10.2215/CJN.06960712

67. Sato A, Saruta T. Aldosterone escape during angiotensin-converting enzyme inhibitor therapy in essential hypertensive patients with left ventricular hypertrophy. J Int Med Res (2001) 29(1):13-21. doi:10.1177/147323000 102900103

68. Alderman MH, Madhavan S, Ooi WL, Cohen H, Sealey JE, Laragh JH. Association of the renin-sodium profile with the risk of myocardial infarction in patients with hypertension. N Engl J Med (1991) 324(16):1098-104. doi:10.1056/NEJM199104183241605

69. Alderman MH. Evidence relating dietary sodium to cardiovascular disease. J Am Coll Nutr (2006) 25(3 Suppl):256S-61S. doi:10.1080/07315724.2006. 10719575

70. He FJ, Markandu ND, MacGregor GA. Importance of the renin system for determining blood pressure fall with acute salt restriction in hypertensive and normotensive whites. Hypertension (2001) 38(3):321-5. doi:10.1161/01. HYP.38.3.321

71. Graudal NA, Hubeck G, Jurgens G. Effects of low-sodium diet vs. high-sodium diet on blood pressure, renin, aldosterone, catecholamines, cholesterol, and triglyceride (cochrane review). Am J Hypertens (2012) 25:1-15. doi:10.1038/ ajh.2011.210

72. Libianto R, Jerums G, Lam Q, Chen A, Baqar S, Pyrlis F, et al. Relationship between urinary sodium excretion and serum aldosterone in patients with diabetes in the presence and absence of modifiers of the renin-angiotensin-aldosterone system. Clin Sci (Lond) (2014) 126(2):147-54. doi:10.1042/CS20130128

73. Chen AX, Jerums G, Baqar S, Lambert E, Somarajah G, Thomas G, et al. Short-term dietary salt supplementation blunts telmisartan induced increases in plasma renin activity in hypertensive patients with type 2 diabetes mellitus. Clin Sci (Lond) (2015) 129(5):415-22. doi:10.1042/CS20140536

74. Ruppert M, Diehl J, Kolloch R, Overlack A, Kraft K, Göbel B, et al. Shortterm dietary sodium restriction increases serum lipids and insulin in salt-sensitive and salt-resistant normotensive adults. Klin Wochenschr (1991) 69(Suppl 25):51-7.

75. Sharma AM, Arntz HR, Kribben A, Schattenfroh S, Distler A. Dietary sodium restriction: adverse effect on plasma lipids. Klin Wochenschr (1990) 68(13):664-8. doi:10.1007/BF01667013

76. Kannel WB, McGee D, Gordon T. A general cardiovascular risk profile: the Framingham Study. Am J Cardiol (1976) 38(1):46-51. doi:10.1016/ 0002-9149(76)90061-8

77. Ruppert M, Overlack A, Kolloch R, Kraft K, Lennarz M, Stumpe KO. Effects of severe and moderate salt restriction on serum lipids in nonobese normotensive adults. Am J Med Sci (1994) 307(Suppl 1):S87-90. 
78. Meland E, Laerum E, Aakvaag A, Ulvik RJ, Høstmark AT. Salt restriction: effects on lipids and insulin production in hypertensive patients. Scand J Clin Lab Invest (1997) 57(6):501-5. doi:10.3109/00365519709084600

79. Aburto NJ,Ziolkovska A, Hooper L, Elliott P, Cappuccio FP, MeerpohlJJ. Effect of lower sodium intake on health: systematic review and meta-analyses. BMJ (2013) 346:20. doi:10.1136/bmj.f1326

80. Townsend RR, Kapoor S, McFadden CB. Salt intake and insulin sensitivity in healthy human volunteers. Clin Sci (Lond) (2007) 113(3):141-8. doi:10.1042/ CS20060361

81. Jamerson KA, Julius S, Gudbrandsson T, Andersson O, Brant DO. Reflex sympathetic activation induces acute insulin resistance in the human forearm. Hypertension (1993) 21(5):618-23. doi:10.1161/01.HYP.21.5.618

82. Underwood PC, Adler GK. The renin angiotensin aldosterone system and insulin resistance in humans. Curr Hypertens Rep (2013) 15(1):59-70. doi:10.1007/s11906-012-0323-2

83. Huggett RJ, Scott EM, Gilbey SG, Bannister J, Mackintosh AF, Mary DA. Disparity of autonomic control in type 2 diabetes mellitus. Diabetologia (2005) 48(1):172-9. doi:10.1007/s00125-004-1601-6

84. Garg R, Williams GH, Hurwitz S, Brown NJ, Hopkins PN, Adler GK. Lowsalt diet increases insulin resistance in healthy subjects. Metabolism (2011) 60:965-8. doi:10.1016/j.metabol.2010.09.005

85. Shanik MH, Xu Y, Škrha J, Dankner R, Zick Y, Roth J. Insulin resistance and hyperinsulinemia. Is hyperinsulinemia the cart or the horse? Diabetes Care (2008) 31(Suppl 2):S262-8. doi:10.2337/dc08-s264

86. Ames RP. The effect of sodium supplementation on glucose tolerance and insulin concentrations in patients with hypertension and diabetes mellitus. Am JHypertens (2001) 14(7 Pt 1):653-9. doi:10.1016/ S0895-7061(01)01310-3

87. Mancia G, Grassi G, Giannattasio C, Seravalle G. Sympathetic activation in the pathogenesis of hypertension and progression of organ damage. Hypertension (1999) 34(4 Pt 2):724-8. doi:10.1161/01.HYP.34.4.724

88. Bertisch SM, Taylor JA. Caveat utilitor: take measure of your marker. J Physiol (2011) 589(Pt 22):5341. doi:10.1113/jphysiol.2011.221770

89. Edwards DG, Farquhar WB. Vascular effects of dietary salt. Curr Opin Nephrol Hypertens (2015) 24(1):8-13. doi:10.1097/MNH.0000000000000089

90. Ross R. The pathogenesis of atherosclerosis: a perspective for the 1990s. Nature (1993) 362(6423):801-9. doi:10.1038/362801a0

91. Lenda DM, Sauls BA, Boegehold MA. Reactive oxygen species may contribute to reduced endothelium-dependent dilation in rats fed high salt. Am J Physiol Heart Circ Physiol (2000) 279(1):H7-14.

92. Lenda DM, Boegehold MA. Effect of a high-salt diet on oxidant enzyme activity in skeletal muscle microcirculation. Am J Physiol (2002) 282(2):H395-402. doi:10.1152/ajpheart.00354.2001

93. Huang A, Yan C, Suematsu N, Cuevas A, Yang Y-M, Kertowidjojo E, et al. Impaired flow-induced dilation of coronary arterioles of dogs fed a low-salt diet: roles of ANG II, PKC, and NAD(P)H oxidase. Am J Physiol Heart Circ Physiol (2010) 299(5):H1476-83. doi:10.1152/ajpheart.01250.2009

94. Tikellis C, Pickering RJ, Tsorotes D, Harjutsalo V, Thorn L, Ahola A, et al. Association of dietary sodium intake with atherogenesis in experimental diabetes and with cardiovascular disease in patients with Type 1 diabetes. Clin Sci (Lond) (2013) 124(10):617-26. doi:10.1042/CS20120352

95. Tikellis C, Pickering RJ, Tsorotes D, Huet O, Chin-Dusting J, Cooper ME, et al. Activation of the renin-angiotensin system mediates the effects of dietary salt intake on atherogenesis in the apolipoprotein Eknockout mouse. Hypertension (2012) 60(1):98. doi:10.1161/HYPERTENSIONAHA.112.191767

96. DuPont JJ, Greaney JL, Wenner MM, Lennon-Edwards SL, Sanders PW, Farquhar WB, et al. High dietary sodium intake impairs endothelium-dependent dilation in healthy salt-resistant humans. J Hypertens (2013) 31(3):530-6. doi:10.1097/HJH.0b013e32835c6ca8

97. Tzemos N, Lim PO, Wong S, Struthers AD, MacDonald TM. Adverse cardiovascular effects of acute salt loading in young normotensive individuals. Hypertension (2008) 51(6):1525-30. doi:10.1161/ HYPERTENSIONAHA.108.109868

98. Dickinson KM, Clifton PM, Keogh JB. A reduction of $3 \mathrm{~g} /$ day from a usual $9 \mathrm{~g} /$ day salt diet improves endothelial function and decreases endothelin-1 in a randomised cross_over study in normotensive overweight and obese subjects. Atherosclerosis (2014) 233:32-8. doi:10.1016/ j.atherosclerosis.2013.11.078
99. Jablonski KL, Racine ML, Geolfos CJ, Gates PE, Chonchol M, McQueen $\mathrm{MB}$, et al. Dietary sodium restriction reverses vascular endothelial dysfunction in middle-aged/older adults with moderately elevated systolic blood pressure. J Am Coll Cardiol (2013) 61(3):335-43. doi:10.1016/j.jacc. 2012.09.010

100. Juan L, White J, Ling G, Xiaomin Z, Jiafu W, Smart EJ, et al. Salt inactivates endothelial nitric oxide synthase in endothelial cells. J Nutr (2009) 139(3):447-51. doi:10.3945/jn.108.097451

101. Omland T, Johnson W, Gordon MB, Creager MA. Endothelial function during stimulation of renin-angiotensin system by low-sodium diet in humans. Am J Physiol (2001) 280(5):H2248-54.

102. García-Ortiz L, Recio-Rodríguez JI, Rodríguez-Sánchez E, Patino-Alonso MC, Agudo-Conde C, Rodríguez-Martín C, et al. Sodium and potassium intake present a J-shaped relationship with arterial stiffness and carotid intima-media thickness. Atherosclerosis (2012) 225:497-503. doi:10.1016/ j.atherosclerosis.2012.09.038

103. Gaarder M, Seierstad T. Measurements of carotid intima media thickness in non-invasive high-frequency ultrasound images: the effect of dynamic range setting. Cardiovasc Ultrasound (2015) 13(1):5. doi:10.1186/14767120-13-5

104. Binger KJ, Gebhardt M, Heinig M, Rintisch C, Schroeder A, Neuhofer W, et al. High salt reduces the activation of IL-4- and IL-13-stimulated macrophages. J Clin Invest (2015) 125(11):4223-38. doi:10.1172/JCI80919

105. Chen S, Agrawal DK. Dysregulation of T cell subsets in the pathogenesis of hypertension. Curr Hypertens Rep (2015) 17(2):8. doi:10.1007/ s11906-014-0521-1

106. Yi B, Titze J, Rykova M, Feuerecker M, Vassilieva G, Nichiporuk I, et al. Effects of dietary salt levels on monocytic cells and immune responses in healthy human subjects: a longitudinal study. Transl Res (2015) 166:103-10. doi:10.1016/j.trsl.2014.11.007

107. Hernandez AL, Kitz A, Wu C, Lowther DE, Rodriguez DM, Vudattu N, et al. Sodium chloride inhibits the suppressive function of FOXP3+ regulatory T cells. J Clin Invest (2015) 125(11):4212-22. doi:10.1172/JCI81151

108. Wu C, Yosef N, Thalhamer T, Zhu C, Xiao S, Kishi Y, et al. Induction of pathogenic TH17 cells by inducible salt-sensing kinase SGK1. Nature (2013) 496(7446):513-7. doi:10.1038/nature11984

109. Kleinewietfeld M, Manzel A, Titze J, Kvakan H, Yosef N, Linker RA, et al. Sodium chloride drives autoimmune disease by the induction of pathogenic TH17 cells. Nature (2013) 496(7446):518-22. doi:10.1038/nature11868

110. Olson NC, Sallam R, Doyle MF, Tracy RP, Huber SA. T helper cell polarization in healthy people: implications for cardiovascular disease. J Cardiovasc Transl Res (2013) 6(5):772-86. doi:10.1007/s12265-013-9496-6

111. Tabas I, Williams KJ, Boren J. Subendothelial lipoprotein retention as the initiating process in atherosclerosis: update and therapeutic implications. Circulation (2007) 116(16):1832-44. doi:10.1161/CIRCULATIONAHA. 106.676890

112. Hansson GK, Libby P. The immune response in atherosclerosis: a double-edged sword. Nat Rev Immunol (2006) 6(7):508-19. doi:10.1038/ nri1882

113. Frostegard J, Ulfgren AK, Nyberg P, Hedin U, Swedenborg J, Andersson U, et al. Cytokine expression in advanced human atherosclerotic plaques: dominance of pro-inflammatory (Th1) and macrophage-stimulating cytokines. Atherosclerosis (1999) 145(1):33-43. doi:10.1016/S0021-9150(99)00011-8

114. Zhou X. CD4+ T cells in atherosclerosis. Biomed Pharmacother (2003) 57(7):287-91. doi:10.1016/S0753-3322(03)00082-9

115. Davenport P, Tipping PG. The role of interleukin-4 and interleukin-12 in the progression of atherosclerosis in apolipoprotein E-deficient mice. Am J Pathol (2003) 163(3):1117-25. doi:10.1016/S0002-9440(10)63471-2

116. King VL, Cassis LA, Daugherty A. Interleukin-4 does not influence development of hypercholesterolemia or angiotensin II-induced atherosclerotic lesions in mice. Am J Pathol (2007) 171(6):2040-7. doi:10.2353/ ajpath.2007.060857

117. Shirai T, Hilhorst M, Harrison DG, Goronzy JJ, Weyand CM. Macrophages in vascular inflammation - from atherosclerosis to vasculitis. Autoimmunity (2015) 48(3):139-51. doi:10.3109/08916934.2015.1027815

118. Abais-Battad JM, Rudemiller NP, Mattson DL. Hypertension and immunity: mechanisms of T cell activation and pathways of hypertension. Curr Opin NephrolHypertens (2015) 24(5):470-4.doi:10.1097/MNH.0000000000000146 
119. Zhang J, Crowley SD. Role of T lymphocytes in hypertension. Curr Opin Pharmacol (2015) 21:14-9. doi:10.1016/j.coph.2014.12.003

120. Wynn TA, Chawla A, Pollard JW. Macrophage biology in development, homeostasis and disease. Nature (2013) 496(7446):445-55. doi:10.1038/ nature 12034

121. Jantsch J, Schatz V, Friedrich D, Schröder A, Kopp C, Siegert I, et al. Cutaneous $\mathrm{Na}+$ storage strengthens the antimicrobial barrier function of the skin and boosts macrophage-driven host defense. Cell Metab (2015) 21(3):493-501. doi:10.1016/j.cmet.2015.02.003

122. Zhou X, Zhang L, Ji WJ, Yuan F, Guo ZZ, Pang B, et al. Variation in dietary salt intake induces coordinated dynamics of monocyte subsets and monocyte-platelet aggregates in humans: implications in end organ inflammation. PLoS One (2013) 8(4):e60332. doi:10.1371/journal. pone. 0060332

123. Shantsila E, Lip GY. The role of monocytes in thrombotic disorders. Insights from tissue factor, monocyte-platelet aggregates and novel mechanisms. Thromb Haemost (2009) 102(5):916-24. doi:10.1160/TH09-01-0023

124. Whelton PK. Dietary sodium intake: scientific basis for public policy. Blood Purif (2015) 39(1-3):16-20. doi:10.1159/000368975

125. Kalogeropoulos AP, Georgiopoulou VV, Murphy RA, Newman AB, Bauer DC, Harris TB, et al. Dietary sodium content, mortality, and risk for cardiovascular events in older adults: the health, aging, and body composition (Health ABC) study. JAMA Intern Med (2015) 175(3):410-9. doi:10.1001/ jamainternmed.2014.6278

126. Taylor RS, Ashton KE, Moxham T, Hooper L, Ebrahim S. Reduced dietary salt for the prevention of cardiovascular disease: a meta-analysis of randomized controlled trials (Cochrane review). Am J Hypertens (2011) 24(8):843-53. doi:10.1038/ajh.2011.115

127. He J, Ogden LG, Vupputuri S, Bazzano LA, Loria C, Whelton PK. Dietary sodium intake and subsequent risk of cardiovascular disease in overweight adults. JAMA (1999) 282(21):2027-34. doi:10.1001/jama.282.21.2027

128. Bibbins-Domingo K, Chertow GM, Coxson PG, Moran A, Lightwood $\mathrm{JM}$, Pletcher MJ, et al. Projected effect of dietary salt reductions on future cardiovascular disease. N Engl J Med (2010) 362(7):590-9. doi:10.1056/ NEJMoa0907355

129. Cook NR, Appel LJ, Whelton PK. Sodium intake and all-cause mortality over 20 years in the trials of hypertension prevention. J Am Coll Cardiol (2016) 68(15):1609-17. doi:10.1016/j.jacc.2016.07.745

130. Cook NR, Cutler JA, Obarzanek E, Buring JE, Rexrode KM, Kumanyika SK, et al. Long term effects of dietary sodium reduction on cardiovascular disease outcomes: observational follow-up of the trials of hypertension prevention (TOHP). BMJ (2007) 334(7599):885-8. doi:10.1136/ bmj.39147.604896.55

131. Gardener H, Rundek T, Wright CB, Elkind MS, Sacco RL. Dietary sodium and risk of stroke in the Northern Manhattan study. Stroke (2012) 43(5):1200-5. doi:10.1161/STROKEAHA.111.641043

132. Strazzullo P, D'Elia L, Kandala NB, Cappuccio FP. Salt intake, stroke, and cardiovascular disease: meta-analysis of prospective studies. BMJ (2009) 339:b4567. doi:10.1136/bmj.b4567

133. Tomonari T, Fukuda M, Miura T, Mizuno M, Wakamatsu TY, Ichikawa $\mathrm{T}$, et al. Research article: is salt intake an independent risk factor of stroke mortality? Demographic analysis by regions in Japan. J Am Soc Hypertens (2011) 5:456-62. doi:10.1016/j.jash.2011.07.004

134. Tuomilehto J, Jousilahti P, Rastenyte D, Moltchanov V, Tanskanen A, Pietinen P, et al. Urinary sodium excretion and cardiovascular mortality in Finland: a prospective study. Lancet (2001) 357(9259):848-51. doi:10.1016/ S0140-6736(00)04199-4

135. Zhao X, Yang X, Zhang X, Li Y, Zhao X, Ren L, et al. Dietary salt intake and coronary atherosclerosis in patients with prehypertension. J Clin Hypertens (Greenwich) (2014) 16(8):575-80. doi:10.1111/jch.12362

136. Ekinci EI, Clarke S, Thomas MC, Moran JL, Cheong K, MacIsaac RJ, et al. Dietary salt intake and mortality in patients with type 2 diabetes. Diabetes Care (2011) 34(3):703-9. doi:10.2337/dc10-1723

137. Ekinci EI, Moran JL, Thomas MC, Cheong K, Clarke S, Chen A, et al. Relationship between urinary sodium excretion over time and mortality in type 2 diabetes. Diabetes Care (2014) 37(4):e62-3. doi:10.2337/dc13-1947

138. Stolarz-Skrzypek K, Kuznetsova T, Thijs L, Tikhonoff V, Seidlerova J, Richart $\mathrm{T}$, et al. Fatal and nonfatal outcomes, incidence of hypertension, and blood pressure changes in relation to urinary sodium excretion. J Am Med Assoc (2011) 305(17):1777-85. doi:10.1001/jama.2011.574

139. Alderman MH, Cohen H, Madhavan S. Dietary sodium intake and mortality: the National Health and Nutrition Examination Survey (NHANES I). Lancet (1998) 351(9105):781-5. doi:10.1016/S0140-6736(97)09092-2

140. O’Donnell M, Mente A, Rangarajan S, McQueen MJ, Wang X, Liu L, et al. Urinary sodium and potassium excretion, mortality, and cardiovascular events. N Engl JMed (2014) 371(7):612-23. doi:10.1056/ NEJMoa1311889

141. Graudal N, Jurgens G, Baslund B, Alderman MH. Compared with usual sodium intake, low- and excessive-sodium diets are associated with increased mortality: a meta-analysis. Am J Hypertens (2014) 27(9):1129-37. doi:10.1093/ajh/hpu028

142. Pfister R, Michels G, Sharp SJ, Luben R, Wareham NJ, Khaw KT. Estimated urinary sodium excretion and risk of heart failure in men and women in the EPIC-Norfolk study. Eur J Heart Fail (2014) 16(4):394-402. doi:10.1002/ ejhf.56

143. Mente A, O'Donnell M, Rangarajan S, Dagenais G, Lear S, McQueen $\mathrm{M}$, et al. Associations of urinary sodium excretion with cardiovascular events in individuals with and without hypertension: a pooled analysis of data from four studies. Lancet (2016) 388(10043):465-75. doi:10.1016/ S0140-6736(16)30467-6

144. Thomas MC, Moran J, Forsblom C, Harjutsalo V, Thorn L, Ahola A, et al. The association between dietary sodium intake, ESRD, and all-cause mortality in patients with type 1 diabetes. Diabetes Care (2011) 34(4):861-6. doi:10.2337/ dc10-1722

145. El-Atat F, McFarlane SI, Sowers JR. Diabetes, hypertension, and cardiovascular derangements: pathophysiology and management. Curr Hypertens Rep (2004) 6(3):215-23. doi:10.1007/s11906-004-0072-y

146. Tarnow L, Rossing P, Gall MA, Nielsen FS, Parving HH. Prevalence of arterial hypertension in diabetic patients before and after the JNC-V. Diabetes Care (1994) 17(11):1247-51. doi:10.2337/diacare.17.11.1247

147. Provenzano LF, Stark S, Steenkiste A, Piraino B, Sevick MA. Dietary sodium intake in type 2 diabetes. Clin Diabetes (2014) 32(3):106-12. doi:10.2337/ diaclin.32.3.106

148. Beretta-Piccoli C, Weidmann P. Body sodium-blood volume state in nonazotemic diabetes mellitus. Miner Electrolyte Metab (1982) 7(1):36-47.

149. Strojek K, Grzeszczak W, Lacka B, Gorska J, Keller CK, Ritz E. Increased prevalence of salt sensitivity of blood pressure in IDDM with and without microalbuminuria. Diabetologia (1995) 38(12):1443-8. doi:10.1007/ BF00400605

150. Tuck M, Corry D, Trujillo A. Salt-sensitive blood pressure and exaggerated vascular reactivity in the hypertension of diabetes mellitus. Am J Med (1990) 88(3):210-6. doi:10.1016/0002-9343(90)90144-3

151. Huggett RJ, Scott EM, Gilbey SG, Stoker JB, Mackintosh AF, Mary DA. Impact of type 2 diabetes mellitus on sympathetic neural mechanisms in hypertension. Circulation (2003) 108(25):3097-101. doi:10.1161/01. CIR.0000103123.66264.FE

152. Anderson EA, Hoffman RP, Balon TW, Sinkey CA, Mark AL. Hyperinsulinemia produces both sympathetic neural activation and vasodilation in normal humans. J Clin Invest (1991) 87(6):2246-52. doi:10.1172/ JCI115260

153. Marshall SM. Recent advances in diabetic nephropathy. Postgrad Med J (2004) 80(949):624-33. doi:10.1136/pgmj.2004.021287

154. Vallon V, Blantz R, Thomson S. The salt paradox and its possible implications in managing hypertensive diabetic patients. Curr Hypertens Rep (2005) 7(2):141-7. doi:10.1007/s11906-005-0089-x

155. Mogensen CE. Early glomerular hyperfiltration in insulin-dependent diabetics and late nephropathy. Scand J Clin Lab Invest (1986) 46(3):201. doi: $10.3109 / 00365518609083660$

156. Vora JP, Dolben J, Dean JD, Thomas D, Williams JD, Owens DR, et al. Renal hemodynamics in newly presenting non-insulin dependent diabetes mellitus. Kidney Int (1992) 41(4):829-35. doi:10.1038/ki.1992.127

157. Miller JA. Renal responses to sodium restriction in patients with early diabetes mellitus. J Am Soc Nephrol (1997) 8(5):749-55.

158. Vallon V, Richter K, Blantz RC, Thomson S, Osswald H. Glomerular hyperfiltration in experimental diabetes mellitus: potential role of tubular reabsorption. J Am Soc Nephrol (1999) 10(12):2569-76. 
159. Peene B, Benhalima K. Sodium glucose transporter protein 2 inhibitors: focusing on the kidney to treat type 2 diabetes. Ther Adv Endocrinol Metab (2014) 5(5):124-36. doi:10.1177/2042018814553965

160. Krikken JA, Lely AT, Bakker SJL, Navis G. The effect of a shift in sodium intake on renal hemodynamics is determined by body mass index in healthy young men. Kidney Int (2007) 71(3):260-5. doi:10.1038/sj.ki. 5002011

161. Price DA, Porter LE, Gordon M, Fisher ND, De'Oliveira JM, Laffel LM, et al. The paradox of the low-renin state in diabetic nephropathy. J Am Soc Nephrol (1999) 10(11):2382-91.

162. Kotchen TA, Cowley AW Jr, Frohlich ED. Salt in health and disease - a delicate balance. NEngl J Med (2013) 368(13):1229-37. doi:10.1056/NEJMra1212606

163. Groop PH, Thomas MC, Moran JL, Waden J, Thorn LM, Makinen VP, et al. The presence and severity of chronic kidney disease predicts all-cause mortality in type 1 diabetes. Diabetes (2009) 58(7):1651-8. doi:10.2337/ db08-1543
164. Ekinci EI, MacIsaac RJ, Thomas MC, Jerums G. Response to comment on: Ekinci et al. dietary salt intake and mortality in patients with type 2 diabetes. Diabetes care 2011;34:703-709. Diabetes Care (2011) 34(7):e125-e. doi: $10.2337 / \mathrm{dc} 11-0834$

Conflict of Interest Statement: The authors declare that the research was conducted in the absence of any commercial or financial relationships that could be construed as a potential conflict of interest.

Copyright (c) 2016 Kong, Baqar, Jerums and Ekinci. This is an open-access article distributed under the terms of the Creative Commons Attribution License (CC BY). The use, distribution or reproduction in other forums is permitted, provided the original author(s) or licensor are credited and that the original publication in this journal is cited, in accordance with accepted academic practice. No use, distribution or reproduction is permitted which does not comply with these terms. 